Article

\title{
Design and Analysis of Jacket Substructures for Offshore Wind Turbines
}

\author{
I-Wen Chen, Bao-Leng Wong, Yu-Hung Lin, Shiu-Wu Chau and Hsin-Haou Huang * \\ Department of Engineering Science and Ocean Engineering, National Taiwan University, Taipei 106, Taiwan; \\ r03525024@ntu.edu.tw (I-W.C.); r03525073@ntu.edu.tw (B.-L.W.); r02525008@ntu.edu.tw (Y.-H.L.); \\ chausw@ntu.edu.tw (S.-W.C.) \\ * Correspondence: hsinhaouhuang@ntu.edu.tw; Tel.: +886-2-3366-5753; Fax: +886-2-2392-9885 \\ Academic Editor: Frede Blaabjerg \\ Received: 31 January 2016; Accepted: 30 March 2016; Published: 2 April 2016
}

\begin{abstract}
This study focused on investigating various existing types of offshore jacket substructures along with a proposed twisted-tripod jacket type (modified jacket (MJ)-structures). The architectures of the three-leg structure, as well as the patented twisted jacket structure motivated the design of the proposed MJ-structures. The dimensions of the structures were designed iteratively using static stress analysis to ensure that all structures had a similar level of load-carrying capability. The numerical global buckling analyses were performed for all structures after the validation by the scaled-down experiments. The local buckling strength of all compressive members was analyzed using the NORSOK standard. The results showed that the proposed MJ-structures possess excellent structural behavior and few structural nodes and components competitive with the patented twisted jacket structures, while still maintaining the advantages of low material usage similar to the three-leg jacket structures. This study provides alternatives for the initial selection and design of offshore wind turbine substructures for green energy applications.
\end{abstract}

Keywords: offshore wind turbine; jacket structure; static analysis; buckling analysis

\section{Introduction}

The consumption and overdevelopment of fossil energy have caused serious environmental problems and are believed to be some of the critical factors contributing to global warming. Renewable energy, such as solar, wind, geothermal and biomass, are all clean energy with tremendous amounts of resources for electricity generation. It was centuries ago when the technology of wind energy made its first steps. As one of the most developed renewable energy technologies, wind power has become the primary consideration with accelerated growth during the past few decades [1-4]. 2014 was a record year for the wind industry, as annual installations crossed the $50 \mathrm{GW}$ mark for the first time. More than $51 \mathrm{GW}$ of new wind power capacity was brought on line. The big story, of course, was China, installing an astonishing 23 GW in 2014, cornering 45\% of the annual market, mostly onshore [5]. 2014 saw total cumulative installations in the offshore sector rise to nearly 9 GW. Most of all offshore wind installations can be found in European waters. As of 30 June 2015, cumulatively, there are 3072 offshore wind turbines with a combined capacity of 10,393.6 MW fully-grid connected in European waters in 82 wind farms across 11 countries, including demonstration sites [6]. However, governments outside of Europe have set ambitious targets for offshore wind, and development is staring to take off in China, Japan, South Korea, U.S. and, of course, Taiwan.

There are needs to develop associated wind technology, including support structures that can withstand local environmental conditions. Commonly, a few types of offshore wind tower support structures include monopile, gravity, tripod, jacket, tripile and floating types. The type of wind tower is chosen on the basis of two factors: depth of the open sea and the condition of the seabed $[7,8]$. 
Monopile and gravity structures are often found to be the most suitable for constructing in the shallow water region, where the water depth is lower than $30 \mathrm{~m}$. Golightly [9] showed that the monopiles are developed in water depths greater than $30 \mathrm{~m}$. Tripod and jacket structures can be built in transitional water regions, which have a water depth between 30 and $50 \mathrm{~m}$. Floating structures are mostly constructed in deep water regions, where the water depth exceeds $50 \mathrm{~m}[10,11]$. Note that a number of floating wave and offshore wind hybrids have been proposed as a new concept in recent times with the development of floating offshore wind prototypes [12].

The cost of the substructure and foundation was evaluated for approximately $14 \%$ of the total capital expenditures of the offshore wind plant reference project [13]. It has been suggested that using jacket structure rather than others offshore has positive effects, such as low wave and current impact loads on the structure compared to others [14]. In particular, four substructure types (monopile, tripile, tripod and jacket) designed for an average water depth of $70 \mathrm{~m}$ in central Mediterranean waters were compared [15]. The results showed that the jacket type substructure is least expensive considering the cost of procurement and fabrication for the Hurd Bank site (one of the sites considered for wind farms in Malta). In addition, the results of finite element analysis concluded that the jacket was the most hydrodynamically transparent among the four types. All aforementioned results agreed with those in $[16,17]$ and indicated that the jacket type is most attractive for substructures in water depths greater than $30 \mathrm{~m}$ and is the most cost-efficient solution for wind turbines up to $8 \mathrm{MW}$.

A number of traditional jacket substructures have been introduced and investigated, including K-braces, X-braces, Z-braces, subdivided-braces, rhombus-braces and mixed-braces $[18,19]$. For instance, a jacket with Z-braces seems to have less mass of the structure and smaller dynamic forces acting on the structures, as compared to the jacket with X-braces [18]. Tubular joints are widely used for the jacket substructures. The tubular members create a complicated geometry at the intersection of members, i.e., joint-can. Joint-cans can play an important role in the jacket substructures. For extreme loads in the jacket, joint-cans help increase extreme capacity to a certain extent [20]. A well-designed jacket frame equipped with joint-cans dissipates energy much more effectively in comparison with a poorly-designed jacket frame without joint-cans [21]. Buckling of braces will be normally encountered prior to joint failure if the joint-cans were to be carefully designed and constructed [22]. This is rather expected since the buckling of structural members is better understood and controlled than the fracture of joints.

A recently-designed new jacket substructure was invented and patented by Keystone Engineering Inc., called the inward battered guide structure (IBGS), or "twisted jacket" foundation [23-25]. A number of advantages of the IBGS have been suggested, such as the fabrication costs are approximately $20 \%$ less expensive than traditional offshore wind turbine jackets, it has fewer nodes and components compared to a traditional jacket, it is safer and easier to manufacture than a traditional jacket, it is more compact, allowing for more structures to be transported, and it has less offshore welding and underwater work, greatly reducing commercial and schedule risks, etc. [25].

This study compares several jacket substructures on the basis of stress and buckling analysis. In total, 14 substructures categorized into four types were constructed and investigated, including one proposed type. Stress analysis using beam element models, as well as global and local buckling analysis were performed. The results provide insights into development of a novel design for offshore wind turbine substructures.

\section{Design and Specification of Jacket Substructures}

\subsection{Basic Information for Design}

The substructures investigated in the present study were designed and modeled for potentially supporting heavy wind turbines, such as the NREL 5-MW baseline wind turbine [26,27] in the Taiwan Strait with an average water depth $50 \mathrm{~m}$. The wind turbine machine and tower were not of interest in 
the design. The weight of the structures above the tower and loads acting on the wind turbine and tower were simplified in the analysis.

All substructures were initially designed with the assumed dimensions. Stress analyses described in Section 3 were then performed to determine the maximum von Mises stresses in the structures. The dimensions of the structures were iteratively modified so that the maximum stresses generated in all designed structures, under identical load and boundary conditions, fell at a similar level. Note that the iteration procedure did not aim to optimize the structures and was stopped once the maximum stress was found within the expected level.

\subsection{Dimensions of Jacket Substructures}

This study considered 14 jacket substructures categorized into four groups for comparison. Each jacket structure was assumed $70.5 \mathrm{~m}$ in total height installed at a 50.0-m water depth.

First, three traditional jacket substructures (abbreviated as J-structures) were selected as reference structures: namely, X-braces (JX), K-braces (JK) and Z-braces (JZ) (Figure 1a). Second, recently-patented twisted jacket substructures (TJ-structures) were considered [23-25]. Detailed geometrical information, however, was not disclosed anywhere in the patents. Thus, the geometrical information of the TJ-structures assumed in this study should not reflect the real-world cases. Four TJ-structures were considered: namely, $0^{\circ}$ twisted (TJ0), $30^{\circ}$ twisted (TJ30), $60^{\circ}$ twisted (TJ60) and $90^{\circ}$ twisted (TJ90) (Figure 1b).
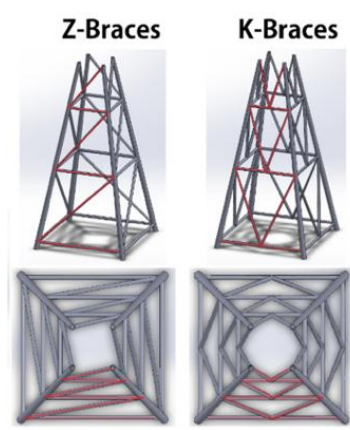

(a)

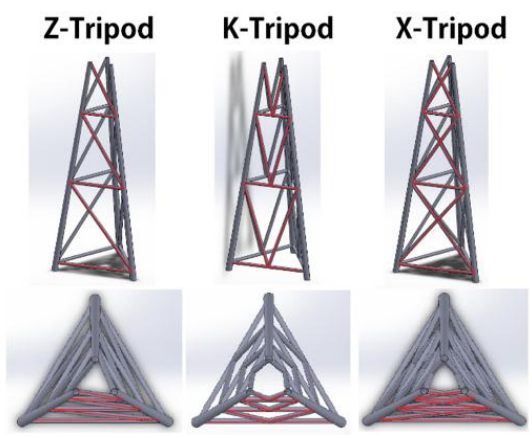

(c)

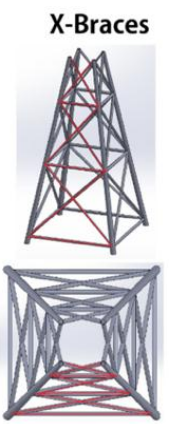

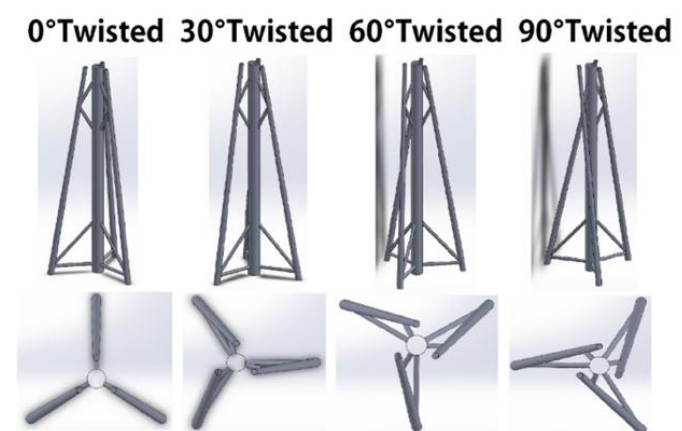

(b)

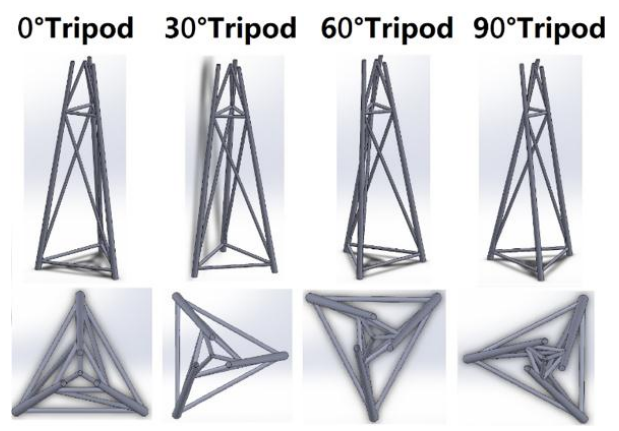

(d)

Figure 1. (a) Traditional jacket substructures (J-structures): Z-braces (JZ), K-braces (JK) and X-braces (JX); (b) twisted jacket substructures (TJ-structures): $0^{\circ}$ twisted (TJ0), 30 ${ }^{\circ}$ twisted (TJ30), $60^{\circ}$ twisted (TJ60) and $90^{\circ}$ twisted (TJ90); (c) tripod jacket substructures (PJ-structures): Z-tripod (PJZ), K-tripod (PJK) and X-tripod (PJX); (d) twisted-tripod jacket substructures (modified jacket (MJ)-structures): $0^{\circ}$ tripod (MJ0), $30^{\circ}$ tripod (MJ30), $60^{\circ}$ tripod (MJ60) and $90^{\circ}$ tripod (MJ90).

The study in [28] concluded that both three- and four-leg jacket substructures are suitable for deep water conditions. It also noted that the designed three-leg jacket is the most lightweight and cost efficient among the studied models. A similar conclusion was reached in a comparison study [29]. We 
thus considered the three-leg jacket substructures (termed tripod jacket structures in the present study, abbreviated PJ-structures) as the third type. Three PJ-structures were considered: namely Z-tripod (PJZ), K-tripod (PJK) and X-tripod (PJX) (Figure 1c). Last, with the advantages of both TJ-structures and PJ-structures taken into consideration (e.g., few structural members, few welded connections, low cost, etc.), a number of twisted tripod jacket structures (or modified jacket structures, abbreviated as MJ-structures) were designed. Similar to the TJ-structures, the MJ-structures were designed with four different twisted angles of the three main structural legs: namely $0^{\circ}$ tripod (MJ0), 30 $60^{\circ}$ tripod (MJ60) and $90^{\circ}$ tripod (MJ90) (Figure 1d). It is noted that the designed MJ-structures are not optimal. Detailed final geometrical information is directed to Appendix A in this paper.

\subsection{Terms and Definitions of Abbreviations for Jacket Members and Parts}

This section lists the abbreviations that will be used hereafter in the study for convenience (Table 1 ). Abbreviations are defined at four levels: (1) $\alpha$, (2) $\beta$, (3) $\gamma$ and (4) $\delta$. Members and parts are termed in the order of $\alpha \beta \gamma$, and the part (location) of the members are termed $\alpha \beta \gamma \delta$. The definitions and examples of the terminology for jacket structural members and parts is directed to Appendix B in this paper.

Table 1. Abbreviations for jacket structure members and parts.

\begin{tabular}{|c|c|c|}
\hline Level & Abbreviation & Definition \\
\hline \multirow{3}{*}{$\alpha$} & I, II, III, IV & First, second, third and fourth face \\
\hline & $a, b, c, d$ & Leg member \\
\hline & e & Central vertical member (for TJ-structures only) \\
\hline$\beta$ & $1,2,3,4$ & First, second, third and fourth layer counting from the top \\
\hline \multirow{4}{*}{$\gamma$} & $\backslash$ and / & Oblique member with " $"$ " and "/" orientation \\
\hline & - & Horizontal member (“-” orientation) \\
\hline & U, I, D & Upper, middle and lower oblique member (for TJ-structures only) \\
\hline & $\mathrm{N}$ & Particularly for leg members \\
\hline$\delta$ & $\mathrm{T}, \mathrm{B}, \mathrm{M}, \mathrm{R}, \mathrm{L}$ & Top, bottom, middle, right and left part \\
\hline
\end{tabular}

\section{Methods of Analysis}

\subsection{Basic Properties}

Commercial finite element software packages, including Abaqus/CAE and Abaqus/Standard, were used for stress and postbuckling analysis. All structures were assumed to be made of structural steel A36, where in the simulations, the density, Young's modulus, Poisson's ratio and yield stress were set to $7800 \mathrm{~kg} / \mathrm{m}^{3}, 200 \mathrm{GPa}, 0.3$ and $250 \mathrm{MPa}$, respectively. Material was assumed linear elastic for all analyses, except for global buckling analysis. The beam element method was employed for stress analysis and local buckling strength check. The modified Riks method with solid and shell elements was employed for unstable collapse and postbuckling analysis. In all analyses, the interaction between soil and structure was neglected, and thus, the structures were assumed fixed in all six degrees of freedom at the bottom.

\subsection{Static Stress Analysis}

The readers should be aware that the analysis of the present study was limited to static methods. Dynamic analyses, including modal analysis and time-domain analysis, as well as fatigue analysis, are important and require additional comprehensive investigation in the future. The beam element type, B31 (2-node linear beam in space), in Abaqus was selected for stress analysis. The maximum mesh size of all jackets was $3 \mathrm{~m}$, such that the element numbers meshed for all jackets range from 151 to 432 . 


\subsubsection{Load Settings}

In general, loads that should be considered for design include permanent, variable, environmental, accidental, etc. $[30,31]$. The overall load combination applied on the whole offshore wind turbine structure is complex in nature and site specific. Since the focus of the present study was on the investigation of the modified substructures and the comparison of those proposed structures with other existing structures, for simplicity and without loss of generality, only permanent load-like mass of the structures and environmental loads, such as wind, wave and current loads, were considered in the analysis. Other environmental loadings, such as tidal, seismic and ice loads, as well as soil conditions and temperature effect, were not taken into account. Two load combinations were considered: normal condition with simplified (2D) loads and extreme condition comprehensive (3D) loads.

\subsubsection{Load Combination 1: Normal Condition with Simplified (2D) Loads}

The normal condition considered in this case refers to local oceanographic data collected near the Pescadores Islands (Penghu). Annual average wind speed, average wave height, average wave period, and average speed of ocean currents were set to $7.5 \mathrm{~m} / \mathrm{s}, 0.49 \mathrm{~m}, 7.5 \mathrm{~s}$ and $0.134 \mathrm{~m} / \mathrm{s}$, respectively, for the normal condition [32].

In this load combination, we simply assumed that the wind, wave and current loads act in the same horizontal direction and that the resultant forces and moment are solely in-plane (Appendix C.4). The combination of simplified (2D) loads includes the self-weight of the 5-MW baseline wind turbine machine and tower, side wind load and wind load moment acting on the top transition piece and the wind load, wave load and current load acting on the substructure. The self-weight of the baseline wind turbine machine and tower refer to [26,27]. It is simplified to a vertical point load acting on the center of the transition piece. The side wind load and wind load moment are effective loads and representative of the wind load acting on the wind turbine machine. They can be simply calculated using elementary mechanics, so long as the wind load acting on the blades and tower are identified. Wave and current loads are calculated using Morison's equation and Airy's linear theory with additional assumptions and approximations. The detailed description of the load settings is directed to Appendix $C$ in this paper.

\subsubsection{Load Combination 2: Extreme Condition with Comprehensive (3D) Loads}

The extreme condition in this case considers the wind speed, wave height, wave period and speed of ocean currents equal to $70 \mathrm{~m} / \mathrm{s}, 14.88 \mathrm{~m}, 12.47 \mathrm{~s}$ and $1.4 \mathrm{~m} / \mathrm{s}$, respectively.

The self-weight of the baseline wind turbine machine and tower was set identical to the first load case. The airflow around a stationary wind turbine is described by the time-averaged continuity and momentum equations together with a $k-\omega$ turbulence model [33]. Therefore, the flow solver StarCCM+ was employed to calculate the fully-three-dimensional flow around the wind turbine at the wind speed of $70 \mathrm{~m} / \mathrm{s}$. Wave and current loads are calculated using Morison's equation and the nonlinear immediate-depth 5th-order Stokes' wave theory. For the three-legged structures (all structures, except J-structures), the wave and current loads were applied in the principal direction (denoted (0)), defined as the positive direction of the $\mathrm{x}$-axis for all three- and four-legged models in Appendix B), whereas for the four-legged structures (J-structures in this study), these loads were applied in the diagonal direction (denoted (45)), because the wave and current loads applied in the diagonal direction generated higher stresses than those applied in the principal direction.

\subsection{Unstable Collapse and Postbuckling Analysis}

The stability of the substructure during and after construction is of particular interest. In this analysis, not only simulations were carried out, but also the experimental validation was conducted using small-scale test specimens. First, the numerical simulation and experiment with scaled-down 
models were performed for validation. Then, full-scale models of all 14 substructures were numerically investigated for the comparison.

\subsubsection{Experiment}

Small-scale experimental validation is an alternative and economic when the full-scale experimental validation is difficult. Three scaled-down test specimens of the MJ0-structure, having a scale of 1:330, made with solid steel tubes, were fabricated (Figure 2a). Because fabrication of the scaled-down specimens with hollow tubes was extremely difficult, solid cross-sections were purposely chosen as an alternation. The MTS 810 materials testing system was used for unidirectional compressive testing. Both the top and bottom ends were slightly inserted in the metal plates to create fixed-end boundary conditions. The displacement-controlled tests were performed, and the compression rate and total displacement of the tests were set to $-0.04 \mathrm{~mm} / \mathrm{s}$ and $-25 \mathrm{~mm}$, respectively (Figure $2 \mathrm{~b}$ ). During each displacement-controlled experiment, the load cell of the MTS machine continuously measured the corresponding applied vertical load on top of the structure, leading to a force-displacement diagram for analysis and comparison.

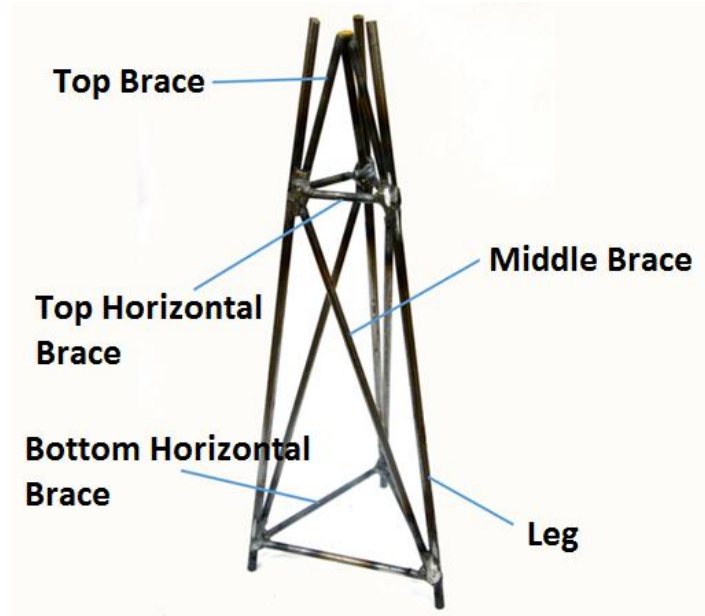

(a)

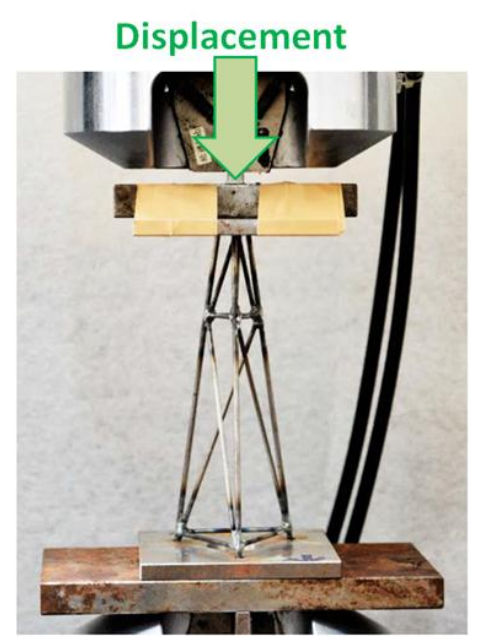

(b)

Figure 2. (a) Schematic of a scaled-down test specimen of the MJ0-structure; (b) snapshot of the experimental setup.

\subsubsection{Numerical Simulation}

The modified Riks method with solid and shell elements in Abaqus was employed for unstable collapse and postbuckling analysis [34]. In simple cases, linear eigenvalue analysis is sufficient for design evaluation. The Riks analysis, a load-deflection analysis method, yields very accurate results for problems with material nonlinearity, geometric nonlinearity prior to buckling or unstable postbuckling response.

The first part was the analysis using the scaled-down model for validation purposes. In the simulation, the material was assumed perfectly plastic, and the properties were defined in Section 3.1. The C3D8R (8-node linear brick, reduced integration with hourglass control) elements were used for the whole scaled-down model with the maximum mesh size equal to $0.025 \mathrm{~mm}$. The applied force, as well as the top and bottom boundaries were set to represent the experiment.

The second part was the analysis of all 14 structures using full-scale models for comparison. The C3D8R (8-node linear brick, reduced integration with hourglass control) elements were used for the transition piece, whereas the S4R (4-node doubly-curved general-purpose shell, reduced integration with hourglass control under finite membrane strains) elements were used for the rest of the substructures. The maximum mesh size of the full-scale models was set to $150 \mathrm{~mm}$. A nonlinear 
load-displacement relation was obtained from each analysis. We defined two points on the obtained nonlinear curve leading to the maximum load and the critical load for comparison purposes. The maximum load is the point with the absolute maximum load of the entire curve, whereas the critical load is the point at which the slope of the curve, i.e., the stiffness of the entire structure in the vertical direction, is $20 \%$ of the initial slope near the origin of the curve. With the two points defined, two loads and the corresponding displacements were obtained. Note that the maximum load is the load that the structure can no longer survive. In addition, determination of the critical load provides additional information that the structure may soon, and how soon to, experience catastrophic collapse.

\subsection{Analysis of Local Buckling Strength Using the NORSOK Standard}

The NORSOK standards are developed by the Norwegian petroleum industry to ensure adequate safety, value adding and cost effectiveness for petroleum industry developments and operations [35]. The standard specifies guidelines and requirements for the design and documentation of offshore steel structures and is applicable to all types of offshore structures made of steel with a specified minimum yield strength less than or equal to $500 \mathrm{MPa}$. Since the offshore steel structures used in the present study follow the standard, it was therefore of interest to check if all structural members in each type satisfy the requirements of the standard specifically in local buckling.

Structural members in all 14 types of substructure are tubular, subjected to combined axial compression and bending loads. The condition without hydrostatic pressure was assumed to meet the simulation conditions. According to the standard, tubular members subjected to combined axial compression and bending should be designed to satisfy the following conditions at all cross-sections along their length:

$$
\begin{gathered}
C_{R 1}=\frac{N_{S d}}{N_{t, R d}}+\frac{\sqrt{M^{2} y, S d}+M_{z, S d}^{2}}{M_{R d}} \leqslant 1.0 \\
C_{R 2}=\frac{N_{S d}}{N_{c, R d}}+\frac{1}{M_{R d}}\left\{\left[\frac{C_{m y} M_{y, S d}}{1-\frac{N_{S d}}{N_{E y}}}\right]^{2}+\left[\frac{C_{m z} M_{z, S d}}{1-\frac{N_{S d}}{N_{E z}}}\right]^{2} \leqslant 1.0\right.
\end{gathered}
$$

where $\mathrm{N}_{\mathrm{Sd}}$ is the design axial force, $\mathrm{N}_{\mathrm{Ey}}$ and $\mathrm{N}_{\mathrm{Ez}}$ are the Euler buckling resistance corresponding to the member $y$ - and z-axis, respectively, $\mathrm{N}_{t, R d}$ is the design axial tension resistance, $\mathrm{N}_{\mathrm{c}, \mathrm{Rd}}$ is the design axial compressive resistance, $\mathrm{M}_{\mathrm{Rd}}$ is the design bending moment resistance, $\mathrm{M}_{\mathrm{y}, S d}$ is the in-plane design bending moment, $M_{z, S d}$ is the out-of-plane design bending moment and $C_{m y}$ and $C_{m z}$ are the reduction factors corresponding to the member y-and z-axis, respectively. Readers are directed to the NORSOK standard for the complete definition of each parameter shown in Equations (1) and (2). Since buckling of structural members is of particular interest in the present study, only members under compression were checked using the aforementioned criteria.

\section{Results and Discussion}

\subsection{Stress Analysis}

The maximum von Mises stresses and their corresponding locations occurring on the structures for 14 substructures under two load cases were obtained from stress analyses (Table 2). The maximum stresses were iteratively obtained, so that the values of all 14 cases fell at a similar level under the extreme condition. The location of the maximum von Mises stresses in all cases on the present designs are also given in Table 2. Notably, the structures were not optimized during the iteration. The maximum stresses can be further decreased by increasing the structural member sizes in all cases. 
Table 2. List of maximum von Mises stresses for 14 substructures under various load settings (denoted (0) and denoted (45)) represent the principal and diagonal directions, respectively).

\begin{tabular}{|c|c|c|c|c|}
\hline \multirow{2}{*}{$\begin{array}{c}\text { Jacket Type } \\
\text { (Wave, Current Directions) }\end{array}$} & \multicolumn{2}{|c|}{ Normal Condition $+2 \mathrm{D}$} & \multicolumn{2}{|c|}{ Extreme Condition + 3D } \\
\hline & $\begin{array}{l}\text { Max. von Mises } \\
\text { Stress (MPa) }\end{array}$ & Location & $\begin{array}{l}\text { Max. von Mises } \\
\text { Stress (MPa) }\end{array}$ & Location \\
\hline $\mathrm{JZ}(0)$ & 18.48 & a4NB & $\mathrm{N} / \mathrm{A}$ & $\mathrm{N} / \mathrm{A}$ \\
\hline JK (0) & 19.81 & a4NB & $\mathrm{N} / \mathrm{A}$ & $\mathrm{N} / \mathrm{A}$ \\
\hline $\mathrm{JX}(0)$ & 21.15 & $\mathrm{a} 4 \mathrm{NB}$ & $\mathrm{N} / \mathrm{A}$ & $\mathrm{N} / \mathrm{A}$ \\
\hline JZ (45) & $\mathrm{N} / \mathrm{A}$ & $\mathrm{N} / \mathrm{A}$ & 32.60 & $\mathrm{II} 3 / \mathrm{M}$ \\
\hline JK (45) & $\mathrm{N} / \mathrm{A}$ & $\mathrm{N} / \mathrm{A}$ & 32.05 & $\mathrm{~b} 4 \mathrm{NB}$ \\
\hline JX (45) & $\mathrm{N} / \mathrm{A}$ & $\mathrm{N} / \mathrm{A}$ & 35.02 & III $\ \backslash \mathrm{T}$ and IIII3 / T \\
\hline TJ0 & 17.10 & a3NB & 32.84 & $\mathrm{a} 3 \mathrm{NB}$ \\
\hline TJ30 & 18.53 & a3NB & 37.26 & a3NT \\
\hline TJ60 & 18.84 & a3NB & 37.59 & $\mathrm{a} 2 \mathrm{DB}$ \\
\hline TJ90 & 19.31 & b3NB & 46.24 & a2IT \\
\hline PJZ & 20.11 & $\mathrm{a} 4 \mathrm{NB}$ & 39.55 & $\mathrm{I} 3 / \mathrm{M}$ \\
\hline PJK & 21.65 & $\mathrm{a} 4 \mathrm{NB}$ & 39.30 & $\mathrm{I} 3 / \mathrm{B}$ \\
\hline PJX & 22.47 & $\mathrm{a} 4 \mathrm{NB}$ & 32.71 & $\mathrm{I} 3 \backslash \mathrm{T}$ \\
\hline MJ0 & 23.04 & a3NB & 45.30 & c2NM \\
\hline MJ30 & 30.19 & a2NT & 39.83 & a3NB \\
\hline MJ60 & 46.53 & I2-L & 41.79 & a2NM \\
\hline MJ90 & 34.62 & II2-L & 39.73 & a2NM \\
\hline
\end{tabular}

\subsection{Unstable Collapse and Postbuckling Analysis}

The first part is the validation of the simulation and experimental results using scaled-down models. Figure $3 \mathrm{a}, \mathrm{b}$ show the after-compression deformation pattern of the scaled-down experimental test specimens and numerical models, respectively. Moreover, the load-displacement curves obtained from both the experimental and numerical tests are illustrated in Figure 3c. The results showed excellent agreement, indicating that the numerical method used for analysis is reliable and the numerical model is highly representative.

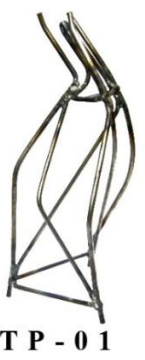

$\mathbf{T} \mathbf{P}-\mathbf{0}$

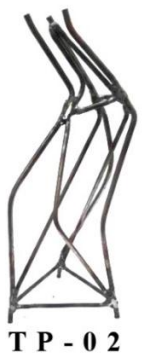

(a)

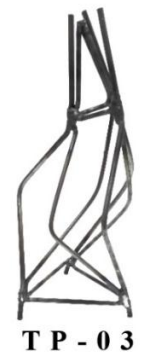

T $\mathbf{P}-\mathbf{0} 3$

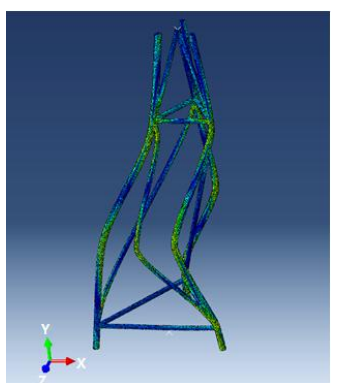

(b)

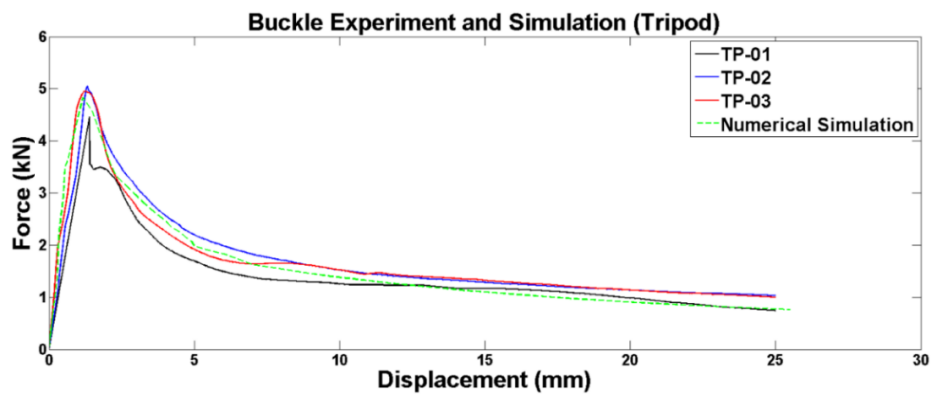

(c)

Figure 3. After compression deformation patterns of the scaled-down (a) experimental test specimens and (b) the numerical model; (c) a diagram of the load-displacement test results from unstable collapse and postbuckling analysis. 
The second part is the analysis of 14 substructures using full-scale models. The force-displacement relations were determined for obtaining the maximum and critical loads and their corresponding vertical displacements (Figure 4). For instance, the force-displacement diagram of the JX-structure (Figure 5) shows that the maximum load and the corresponding displacement are $119.5 \mathrm{MN}$ and $142.0 \mathrm{~mm}$ and that the critical load and the corresponding displacement are $113 \mathrm{MN}$ and $76.8 \mathrm{~mm}$, respectively. The TJ-structures resisted high critical and maximum loads compared to other types, possibly because the TJ-structures consist of a central huge column that is capable of withstanding vertical compressive loads, hence preventing buckling. The proposed MJ-structures are comparable to other types under Riks analysis.

(a) Load(MN)

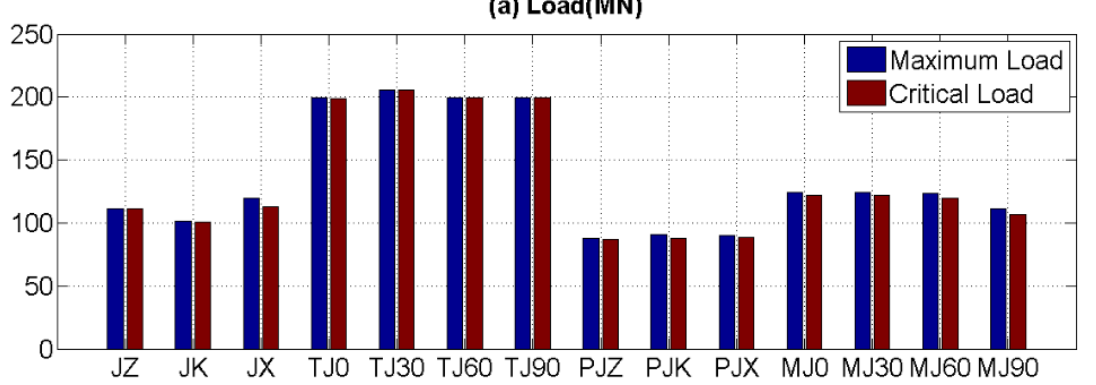

(b) Displacement(mm)

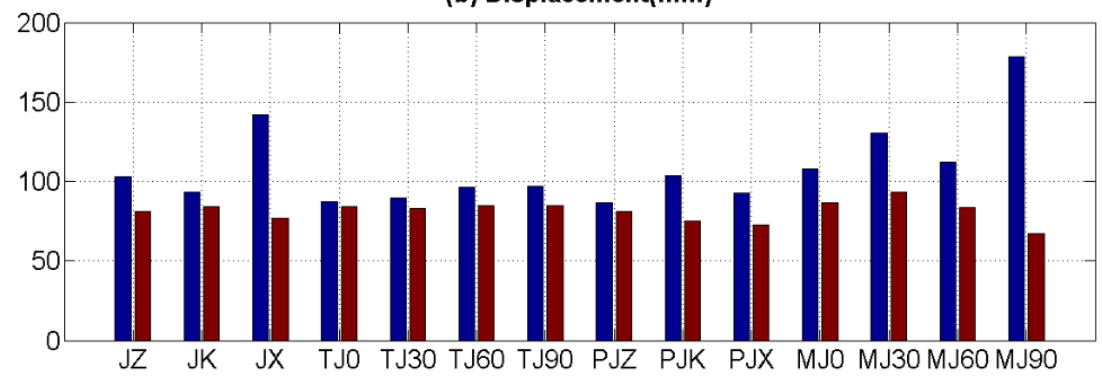

Figure 4. Comparison charts of all 14 jacket structures showing: (a) maximum and critical loads, and; (b) the corresponding displacements under unstable collapse and postbuckling analysis.

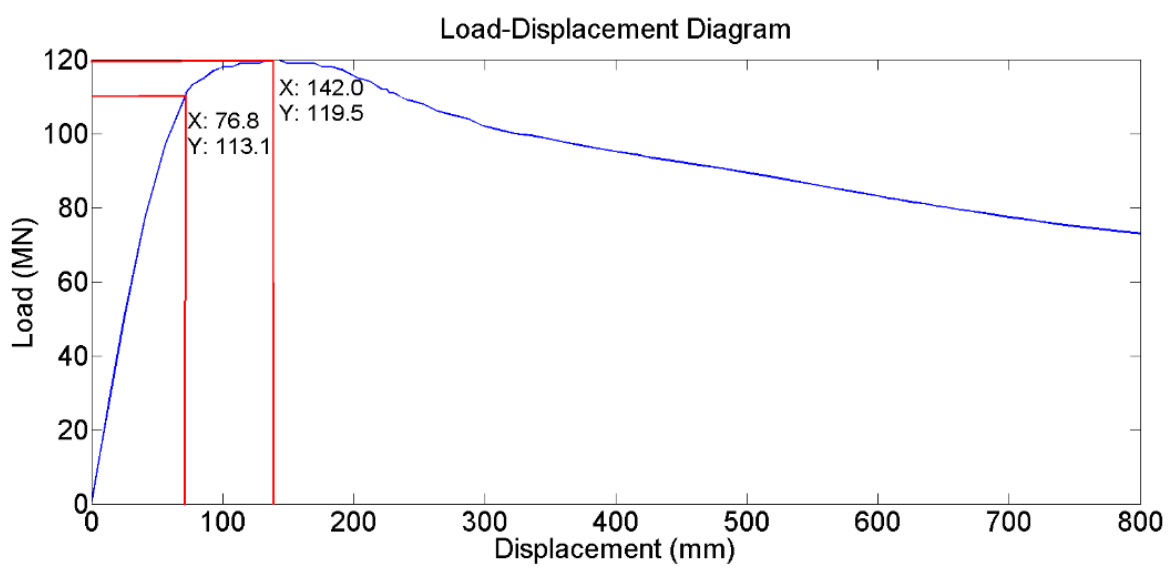

Figure 5. A load-displacement diagram (of the JX-structure) showing the example of the maximum load with the corresponding vertical displacement on the top of the structure (119.5 MN, $142.0 \mathrm{~mm}$ ) and the critical load with the corresponding vertical displacement (113.1 MN, $76.8 \mathrm{~mm}$ ) defined for a full-scale model. 


\subsection{Analysis of Local Buckling Strength}

Let $\left(C_{R, \max }\right)_{j}=\operatorname{Max}\left\{\left(C_{R 1}\right)_{j},\left(C_{R 2}\right)_{j}\right\}$, where $\left(C_{R 1}\right)_{j}$ and $\left(C_{R 2}\right)_{j}$ were obtained using Equations $(1)$ and (2) for the member $j$ of a substructure. Then, the maximum criteria calculated for a substructure with in total $n$ members in compression were obtained as $C_{R, \max }=\operatorname{Max}\left\{\left(C_{R, \max }\right)_{1},\left(C_{R, \max }\right)_{2}, \ldots,\left(C_{R, \max }\right)_{j}\right.$, $\left.\ldots,\left(C_{R, \max }\right)_{n}\right\}$. When the maximum criteria value, $C_{R, \max }$, is greater than one, the corresponding structural member is subjected to local buckling failure. The maximum criteria of 14 substructures are illustrated in Figure 6. The results showed that all structures under the present designs were shown safe from local buckling failure and possessed similar local buckling strength during the comprehensive extreme condition.

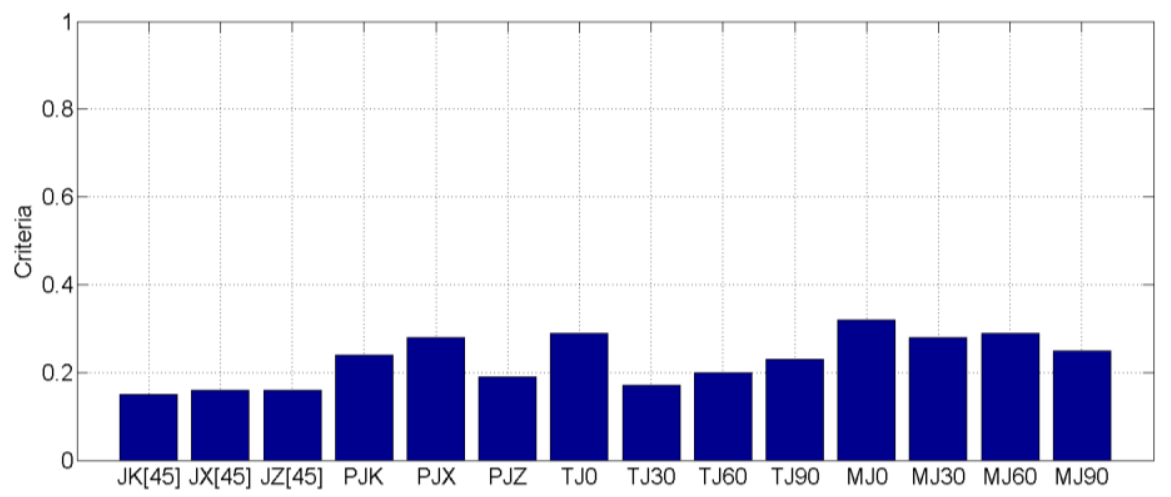

Figure 6. A bar chart showing the maximum criteria for 14 substructures using local buckling strength analysis under the extreme condition with comprehensive (3D) loads.

\subsection{Miscellaneous Properties}

The weight of the structures that straightforwardly leads to the cost of materials and the number of welded joints, which implies the complexity of construction and the risks of fatigue and fracture, both under the present 14 geometrical designs, were also of main concern. Figure 7 shows the ratio of the weight to height, the number of joints and the ratio of joint numbers to floor numbers. The $\mathrm{J}$-structures and PJ-structures were counted as three floors, and the TJ-structures and MJ-structures were counted as two floors.
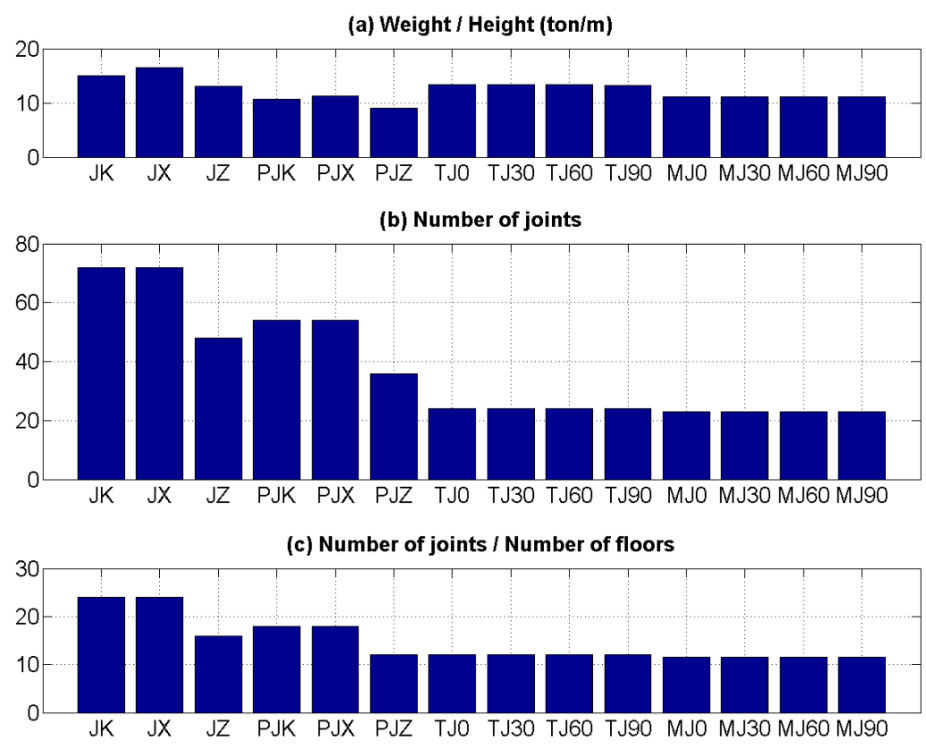

Figure 7. Comparison charts of all 14 jacket structures showing: (a) the ratio of the weight to height; (b) the number of joints; (c) the ratio of joint numbers to floor numbers. 
Under the present designs, the group of J-structures is the heaviest, possessing the greatest number of joints per floor number. The MJ-structures, anticipated to combine both the advantages of TJ- and PJ-structures, are the lightest, simultaneously possessing the least number of joints per floor number. The performance of MJ-structures can be further optimized by increasing the thicknesses and diameters of the structural members or by adjusting the architecture of the substructure to change the slenderness ratio of structural members through iteration.

\section{Conclusions}

In summary, this study presented the investigation of various types of offshore jacket substructures along with a proposed twisted-tripod-jacket type. The dimensions of the structures were decided iteratively using static stress analysis to ensure that all structures had a similar level of load-carrying capability. The numerical global buckling analyses were performed for all structures after being validated by the scaled-down experiments. Analyses of local buckling strength using the NORSOK standard were also of interest. The results revealed that all structures were safe under the provided load combinations. The MJ-structures were expected and proven to possess excellent structural behavior similar to the patented twisted jacket structures, while still maintaining the advantage of low material usage, similar to the three-leg jacket structures. Although the design of offshore wind turbine substructures is site dependent and requires additional dynamic and fatigue analysis with many specific site load combinations, the results obtained in this study shall provide alternatives for the initial selection and design of offshore wind turbine substructures.

Acknowledgments: The help of Yann Quemener, Tsung-Yueh Lin and Chien-Hua Huang from the Research Department of the CR Classification Society (CR) is gratefully acknowledged. This work was financially supported partly by the CR Classification Society (No. 103E31037) and partly by the Ministry of Science and Technology (MOST), Taiwan (Nos. 104-3113-E-002-001 and 105-3113-E-002-001).

Author Contributions: Hsin-Haou Huang conceived of and supervised the study. I-Wen Chen and Bao-Leng Wong performed the simulations. Yu-Hung Lin performed the experiments. Hsin-Haou Huang, I-Wen Chen, Bao-Leng Wong and Yu-Hung Lin analyzed the data. Shiu-Wu Chau generated input load data for the analysis. Hsin-Haou Huang and I-Wen Chen wrote the paper.

Conflicts of Interest: The authors declare no conflict of interest. The funding sponsors had no role in the design of the study; in the collection, analyses or interpretation of data; in the writing of the manuscript; nor in the decision to publish the results.

\section{Abbreviations}

The following abbreviations are used in this manuscript:

J: $\quad$ Traditional jacket substructure

TJ: $\quad$ Twisted jacket substructure

PJ: $\quad$ Tripod jacket substructure

MJ: $\quad$ Twisted-tripod jacket substructure

JZ: $\quad$ Traditional jacket substructure Z-braces

JK: $\quad$ Traditional jacket substructure K-brace

JX: $\quad$ Traditional jacket substructure X-braces

TJ0: $\quad$ Twisted jacket substructures $0^{\circ}$ Twisted

TJ30: $\quad$ Twisted jacket substructures $30^{\circ}$ twisted

TJ60: $\quad$ Twisted jacket substructures $60^{\circ}$ twisted

TJ90: $\quad$ Twisted jacket substructures $90^{\circ}$ twisted

PJZ: $\quad$ Tripod jacket substructures Z-tripod

PJK: $\quad$ Tripod jacket substructures K-tripod

PJX: $\quad$ Tripod jacket substructures X-tripod

MJ0: $\quad$ Twisted-tripod jacket substructures $0^{\circ}$ tripod 
MJ30: $\quad$ Twisted-tripod jacket substructures $0^{\circ}$ tripod

MJ60: $\quad$ Twisted-tripod jacket substructures $60^{\circ}$ tripod

MJ90: $\quad$ Twisted-tripod jacket substructures $90^{\circ}$ tripod

\section{Appendix A. Definitions and Dimensions of Jacket Substructure Members}

Four types of jacket substructure were designed in the study: the traditional jacket substructure $(\mathrm{J})$, the twisted jacket substructure (TJ), the tripod jacket substructure (PJ) and the twisted-tripod jacket substructure (MJ).

\section{A.1. Traditional Jacket Substructure (J-Structure)}

The J-structure is four-legged. The terminology of the structural members is shown in Figure A1. Three J-structures were designed: X-braces (JX), K-braces (JK) and Z-braces (JZ). The dimensions are listed in Table A1. The side and top views of the J-structure are shown in Figure A2 (JX structure shown as an example).

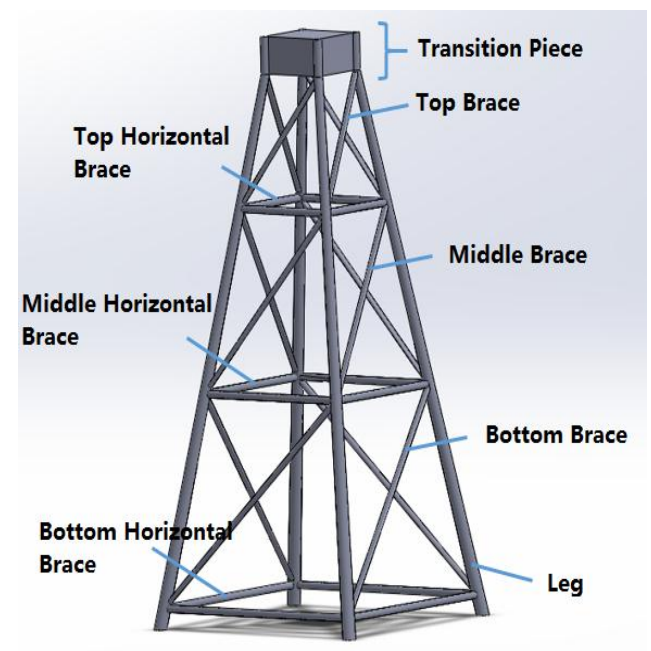

Figure A1. Terminology of the structural members of a J-structure.

Table A1. Specification of three J-structures.

\begin{tabular}{cccc}
\hline \multicolumn{4}{c}{ Traditional Jacket Substructure (J) } \\
\hline Jacket Type & Z-Braces & K-Braces & X-Braces \\
Total Height & $66.00 \mathrm{~m}$ & $66.00 \mathrm{~m}$ & $66.00 \mathrm{~m}$ \\
Length of Leg & $67.97 \mathrm{~m}$ & $67.97 \mathrm{~m}$ & $67.97 \mathrm{~m}$ \\
Length of Top Brace & $20.07 \mathrm{~m}$ & $16.85 \mathrm{~m}$ & $20.07 \mathrm{~m}$ \\
Length of Middle Brace & $28.94 \mathrm{~m}$ & $23.49 \mathrm{~m}$ & $28.94 \mathrm{~m}$ \\
Length of Bottom Brace & $37.18 \mathrm{~m}$ & $28.17 \mathrm{~m}$ & $37.18 \mathrm{~m}$ \\
Length of Top Horizontal Brace & $14.58 \mathrm{~m}$ & $14.58 \mathrm{~m}$ & $14.58 \mathrm{~m}$ \\
Length of Middle Horizontal Brace & $22.24 \mathrm{~m}$ & $22.24 \mathrm{~m}$ & $22.24 \mathrm{~m}$ \\
Length of Bottom Horizontal Brace & $31.13 \mathrm{~m}$ & $31.13 \mathrm{~m}$ & $31.13 \mathrm{~m}$ \\
Thickness of Brace & $0.03 \mathrm{~m}$ & $0.03 \mathrm{~m}$ & $0.03 \mathrm{~m}$ \\
Thickness of Leg & $0.04 \mathrm{~m}$ & $0.04 \mathrm{~m}$ & $0.04 \mathrm{~m}$ \\
Diameter of Brace & $0.90 \mathrm{~m}$ & $0.90 \mathrm{~m}$ & $0.90 \mathrm{~m}$ \\
Diameter of Leg & $1.80 \mathrm{~m}$ & $1.80 \mathrm{~m}$ & $1.80 \mathrm{~m}$ \\
\hline
\end{tabular}




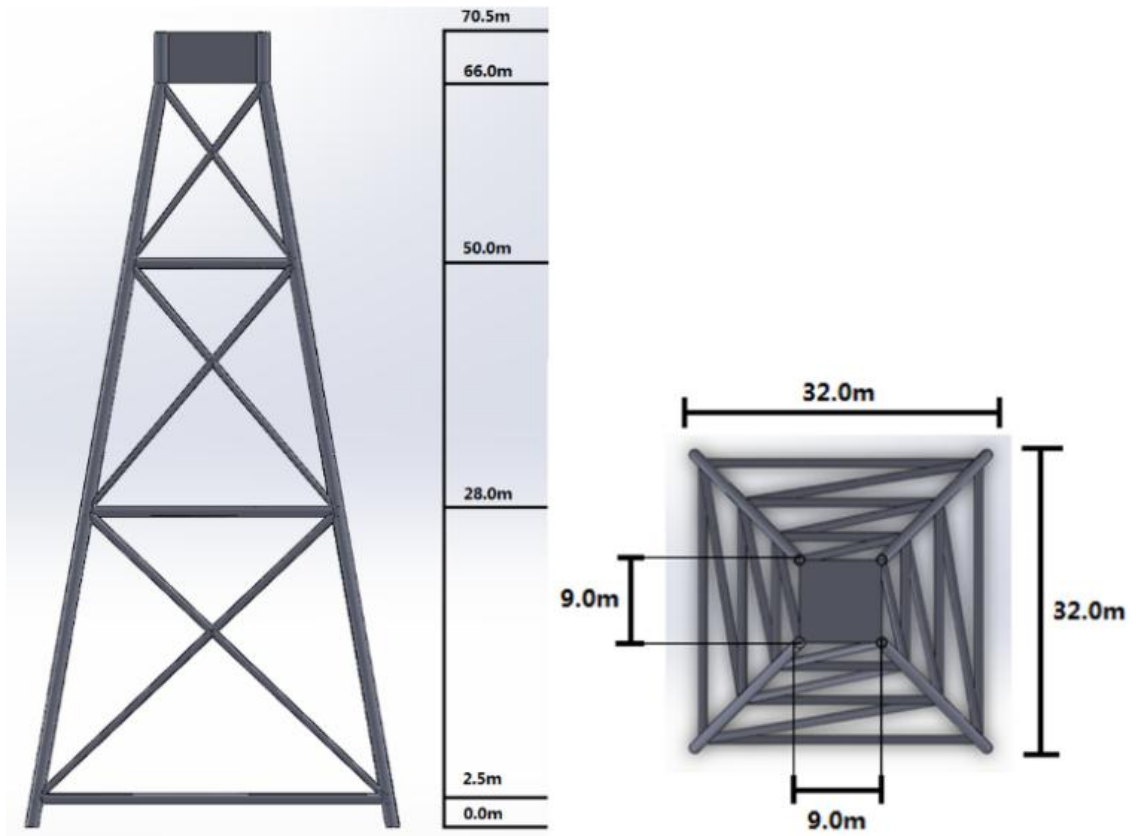

Figure A2. Side and top views of the X-braces (JX) structure.

\section{A.2. Twisted Jacket Substructure (TJ-Structure)}

The terminology of the TJ-structure members is shown in Figure A3. Four TJ-structures were designed: $0^{\circ}$ twisted (TJ0), $30^{\circ}$ twisted (TJ30), $60^{\circ}$ twisted (TJ60) and $90^{\circ}$ twisted (TJ90). In Figure A4, the bottom-end center and the top-end center of a leg are projected to Points A and B on the $\mathrm{x}-\mathrm{z}$ plane, respectively. The center of the central column is projected to Point $\mathrm{O}$ on the same plane. The angle between two vectors, $\overrightarrow{O A}$ and $\overrightarrow{O B}$, is defined as the twisted angle. The dimensions of the TJ-structures are listed in Table A2. The side and top views of the TJ-structure are shown in Figure A4 (TJ30 structure shown as an example).

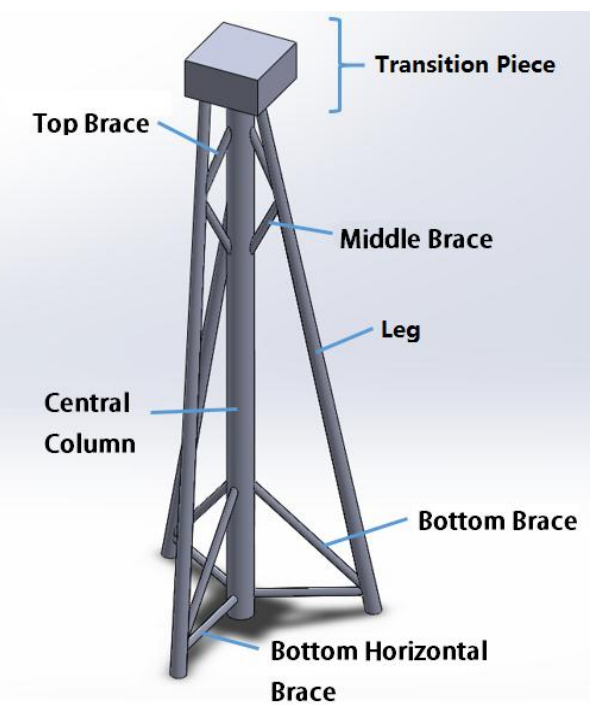

Figure A3. Terminology of the structural members of a TJ-structure. 


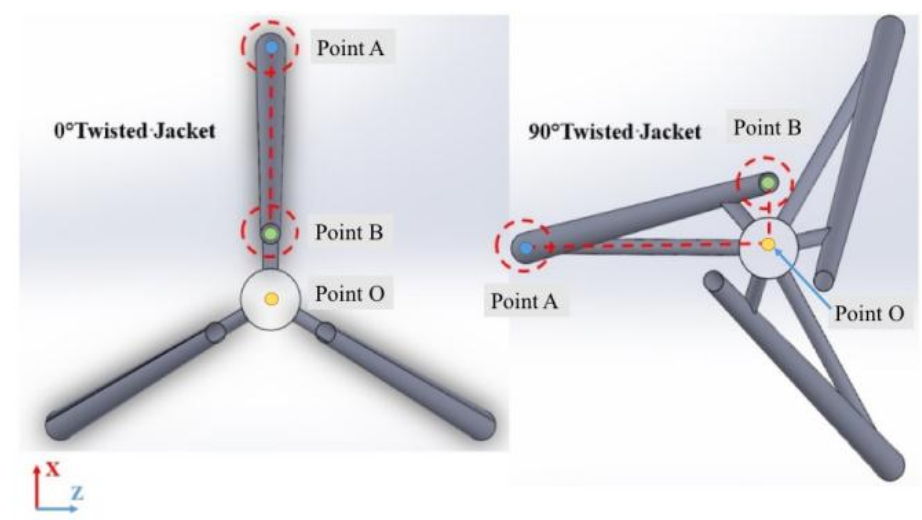

Figure A4. Illustration for the definition of the twisted angle.

Table A2. Specification of four TJ-structures.

\begin{tabular}{ccccc}
\hline \multicolumn{5}{c}{ Twisted Jacket Structure } \\
\hline Jacket Structure & TJ0 & TJ30 & TJ60 & TJ90 \\
Total Height & $66.00 \mathrm{~m}$ & $66.00 \mathrm{~m}$ & $66.00 \mathrm{~m}$ & $66.00 \mathrm{~m}$ \\
Length of Leg & $66.86 \mathrm{~m}$ & $66.97 \mathrm{~m}$ & $67.28 \mathrm{~m}$ & $67.68 \mathrm{~m}$ \\
Length of Top Brace & $11.57 \mathrm{~m}$ & $11.48 \mathrm{~m}$ & $11.20 \mathrm{~m}$ & $10.82 \mathrm{~m}$ \\
Length of Middle Brace & $11.57 \mathrm{~m}$ & $11.48 \mathrm{~m}$ & $11.20 \mathrm{~m}$ & $10.82 \mathrm{~m}$ \\
Length of Bottom Brace & $20.58 \mathrm{~m}$ & $20.57 \mathrm{~m}$ & $20.54 \mathrm{~m}$ & $20.49 \mathrm{~m}$ \\
Length of Bottom Horizontal Brace & $14.09 \mathrm{~m}$ & $14.08 \mathrm{~m}$ & $14.03 \mathrm{~m}$ & $13.95 \mathrm{~m}$ \\
Thickness of Top Brace & $0.04 \mathrm{~m}$ & $0.04 \mathrm{~m}$ & $0.04 \mathrm{~m}$ & $0.04 \mathrm{~m}$ \\
Thickness of Middle Brace & $0.05 \mathrm{~m}$ & $0.05 \mathrm{~m}$ & $0.05 \mathrm{~m}$ & $0.05 \mathrm{~m}$ \\
Thickness of Bottom Brace & $0.05 \mathrm{~m}$ & $0.05 \mathrm{~m}$ & $0.05 \mathrm{~m}$ & $0.05 \mathrm{~m}$ \\
Thickness of Bottom Horizontal Brace & $0.05 \mathrm{~m}$ & $0.05 \mathrm{~m}$ & $0.05 \mathrm{~m}$ & $0.05 \mathrm{~m}$ \\
Thickness of Leg & $0.04 \mathrm{~m}$ & $0.04 \mathrm{~m}$ & $0.04 \mathrm{~m}$ & $0.04 \mathrm{~m}$ \\
Thickness of Central Column & $0.04 \mathrm{~m}$ & $0.04 \mathrm{~m}$ & $0.04 \mathrm{~m}$ & $0.04 \mathrm{~m}$ \\
Diameter of Top Brace & $1.2 \mathrm{~m}$ & $1.2 \mathrm{~m}$ & $1.2 \mathrm{~m}$ & $1.2 \mathrm{~m}$ \\
Diameter of Middle Brace & $1.6 \mathrm{~m}$ & $1.6 \mathrm{~m}$ & $1.6 \mathrm{~m}$ & $1.6 \mathrm{~m}$ \\
Diameter of Bottom Brace & $1.6 \mathrm{~m}$ & $1.6 \mathrm{~m}$ & $1.6 \mathrm{~m}$ & $1.6 \mathrm{~m}$ \\
Diameter of Bottom Horizontal Brace & $1.6 \mathrm{~m}$ & $1.6 \mathrm{~m}$ & $1.6 \mathrm{~m}$ & $1.6 \mathrm{~m}$ \\
Diameter of Leg & $1.80 \mathrm{~m}$ & $1.80 \mathrm{~m}$ & $1.80 \mathrm{~m}$ & $1.80 \mathrm{~m}$ \\
Diameter of Central Column & $3.60 \mathrm{~m}$ & $3.60 \mathrm{~m}$ & $3.60 \mathrm{~m}$ & $3.60 \mathrm{~m}$ \\
\hline
\end{tabular}
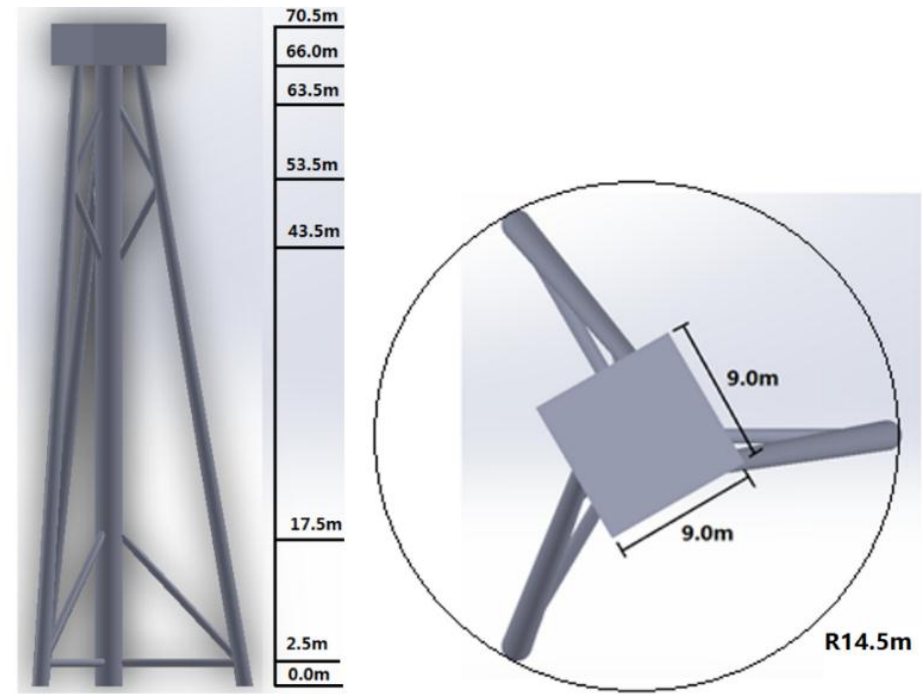

Figure A5. Side and top views of the $0^{\circ}$ twisted (TJ30) structure. 


\section{A.3. Tripod Jacket Substructure (PJ-Structure)}

The terminology of the PJ-structure members is shown in Figure A6. Three PJ-structures were designed: Z-tripod (PJZ), K-tripod (PJK) and X-tripod (PJX). The dimensions of the PJ-structures are listed in Table A3. The side and top views of the PJ-structure are shown in Figure A7 (PJZ structure shown as an example).

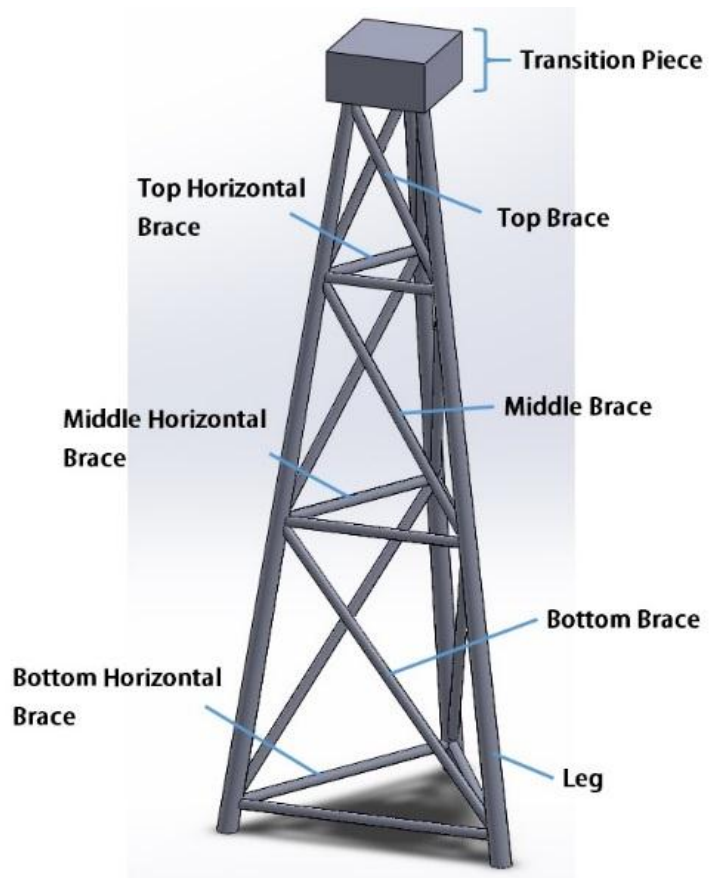

Figure A6. Terminology of the structural members of a PJ-structure.

Table A3. Specification of three PJ-structures.

\begin{tabular}{cccc}
\hline \multicolumn{4}{c}{ Tripod Jacket Substructure (PJ) } \\
\hline Jacket Type & PJZ & PJK & PJX \\
\hline Total Height & $66.00 \mathrm{~m}$ & $66.00 \mathrm{~m}$ & $66.00 \mathrm{~m}$ \\
Length of Leg & $66.86 \mathrm{~m}$ & $66.86 \mathrm{~m}$ & $66.86 \mathrm{~m}$ \\
Length of Top Brace & $18.32 \mathrm{~m}$ & $16.39 \mathrm{~m}$ & $18.32 \mathrm{~m}$ \\
Length of Middle Brace & $26.23 \mathrm{~m}$ & $22.76 \mathrm{~m}$ & $26.23 \mathrm{~m}$ \\
Length of Bottom Brace & $32.99 \mathrm{~m}$ & $27.00 \mathrm{~m}$ & $32.99 \mathrm{~m}$ \\
Length of Top Horizontal Brace & $11.07 \mathrm{~m}$ & $11.07 \mathrm{~m}$ & $11.07 \mathrm{~m}$ \\
Length of Middle Horizontal Brace & $17.25 \mathrm{~m}$ & $17.25 \mathrm{~m}$ & $17.25 \mathrm{~m}$ \\
Length of Bottom Horizontal Brace & $24.41 \mathrm{~m}$ & $24.41 \mathrm{~m}$ & $24.41 \mathrm{~m}$ \\
Thickness of Brace & $0.03 \mathrm{~m}$ & $0.03 \mathrm{~m}$ & $0.03 \mathrm{~m}$ \\
Thickness of Leg & $0.04 \mathrm{~m}$ & $0.04 \mathrm{~m}$ & $0.04 \mathrm{~m}$ \\
Diameter of Brace & $0.90 \mathrm{~m}$ & $0.90 \mathrm{~m}$ & $0.90 \mathrm{~m}$ \\
Diameter of Leg & $1.80 \mathrm{~m}$ & $1.80 \mathrm{~m}$ & $1.80 \mathrm{~m}$ \\
\hline
\end{tabular}



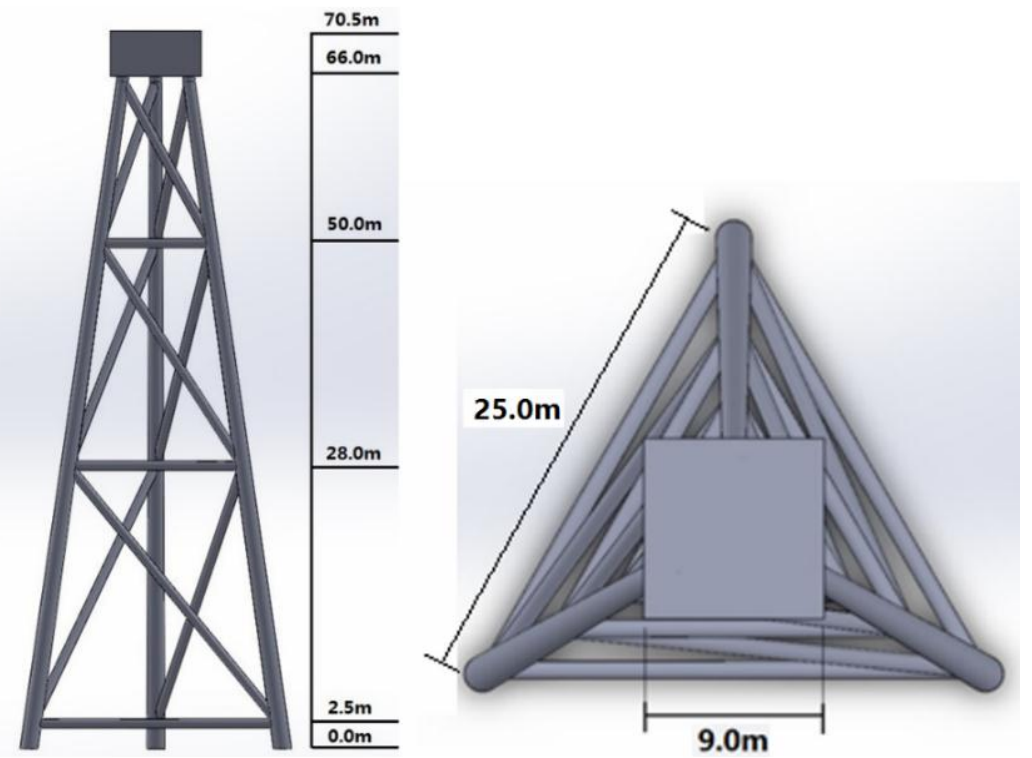

Figure A7. Side and top views of the Z-Tripod (PJZ) structure.

\section{A.4. Twisted-Tripod Jacket Substructure (MJ-Structure)}

The terminology of the MJ-structure members is shown in Figure A8. Four MJ-structures were designed: $0^{\circ}$ tripod (MJ0), $30^{\circ}$ tripod (MJ30), $60^{\circ}$ tripod (MJ60) and $90^{\circ}$ tripod (MJ90). The definition of the twisted angle for the MJ-structures is the same as that for the TJ-structures. The dimensions of the MJ-structures are listed in Table A4. The side and top views of the MJ-structure are shown in Figure A9 (MJ60 structure shown as an example).

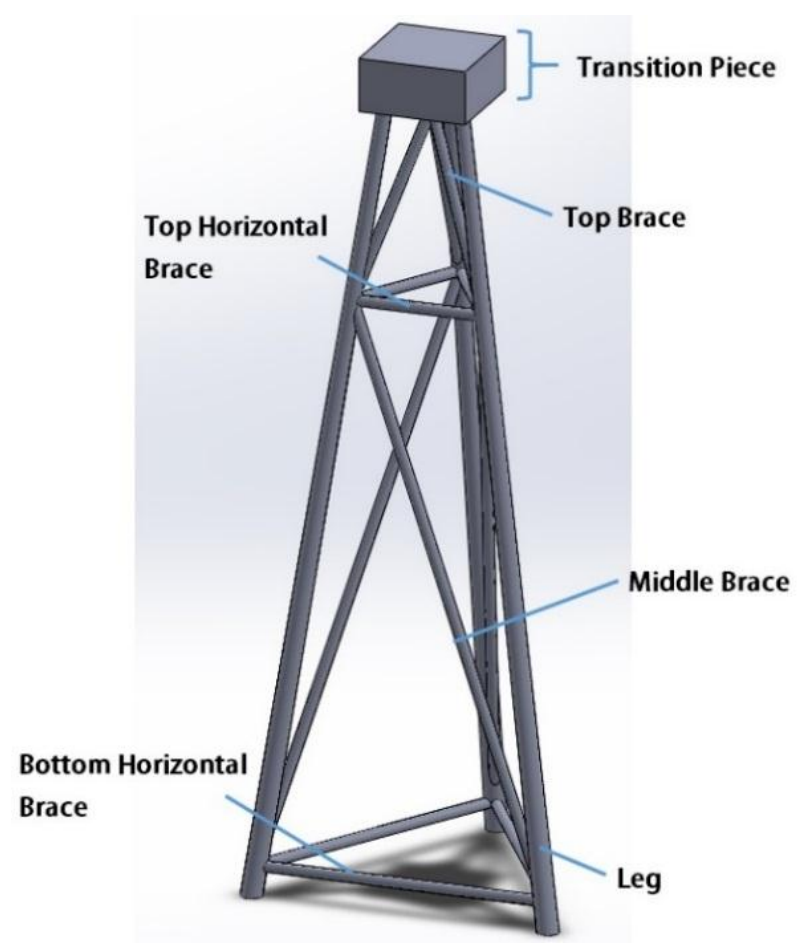

Figure A8. Terminology of the structural members of an MJ-structure. 
Table A4. Specification of four MJ-structures.

\begin{tabular}{ccccc}
\hline \multicolumn{5}{c}{ Twisted Tripod Jacket Substructure (MJ) } \\
\hline Jacket Type & MJ0 & MJ30 & MJ60 & MJ90 \\
\hline Total Height & $66.00 \mathrm{~m}$ & $66.00 \mathrm{~m}$ & $66.00 \mathrm{~m}$ & $66.00 \mathrm{~m}$ \\
Length of Leg & $66.86 \mathrm{~m}$ & $66.97 \mathrm{~m}$ & $67.28 \mathrm{~m}$ & $67.68 \mathrm{~m}$ \\
Length of Top Brace & $17.23 \mathrm{~m}$ & $17.15 \mathrm{~m}$ & $16.93 \mathrm{~m}$ & $16.63 \mathrm{~m}$ \\
Length of Middle Brace & $50.85 \mathrm{~m}$ & $51.10 \mathrm{~m}$ & $51.12 \mathrm{~m}$ & $50.89 \mathrm{~m}$ \\
Length of Top Horizontal Brace & $11.07 \mathrm{~m}$ & $10.70 \mathrm{~m}$ & $9.61 \mathrm{~m}$ & $7.87 \mathrm{~m}$ \\
Length of Bottom Horizontal Brace & $24.41 \mathrm{~m}$ & $24.38 \mathrm{~m}$ & $24.32 \mathrm{~m}$ & $24.16 \mathrm{~m}$ \\
Thickness of Horizontal Brace & $0.03 \mathrm{~m}$ & $0.03 \mathrm{~m}$ & $0.03 \mathrm{~m}$ & $0.03 \mathrm{~m}$ \\
Thickness of Top Brace & $0.06 \mathrm{~m}$ & $0.06 \mathrm{~m}$ & $0.06 \mathrm{~m}$ & $0.06 \mathrm{~m}$ \\
Thickness of Middle Brace & $0.06 \mathrm{~m}$ & $0.06 \mathrm{~m}$ & $0.06 \mathrm{~m}$ & $0.06 \mathrm{~m}$ \\
Thickness of Leg & $0.04 \mathrm{~m}$ & $0.04 \mathrm{~m}$ & $0.04 \mathrm{~m}$ & $0.04 \mathrm{~m}$ \\
Diameter of Horizontal Brace & $0.90 \mathrm{~m}$ & $0.90 \mathrm{~m}$ & $0.90 \mathrm{~m}$ & $0.90 \mathrm{~m}$ \\
Diameter of Top Brace & $0.90 \mathrm{~m}$ & $0.90 \mathrm{~m}$ & $0.90 \mathrm{~m}$ & $0.90 \mathrm{~m}$ \\
Diameter of Middle Brace & $1.20 \mathrm{~m}$ & $1.20 \mathrm{~m}$ & $1.20 \mathrm{~m}$ & $1.20 \mathrm{~m}$ \\
Diameter of Leg & $1.80 \mathrm{~m}$ & $1.80 \mathrm{~m}$ & $1.80 \mathrm{~m}$ & $1.80 \mathrm{~m}$ \\
\hline
\end{tabular}

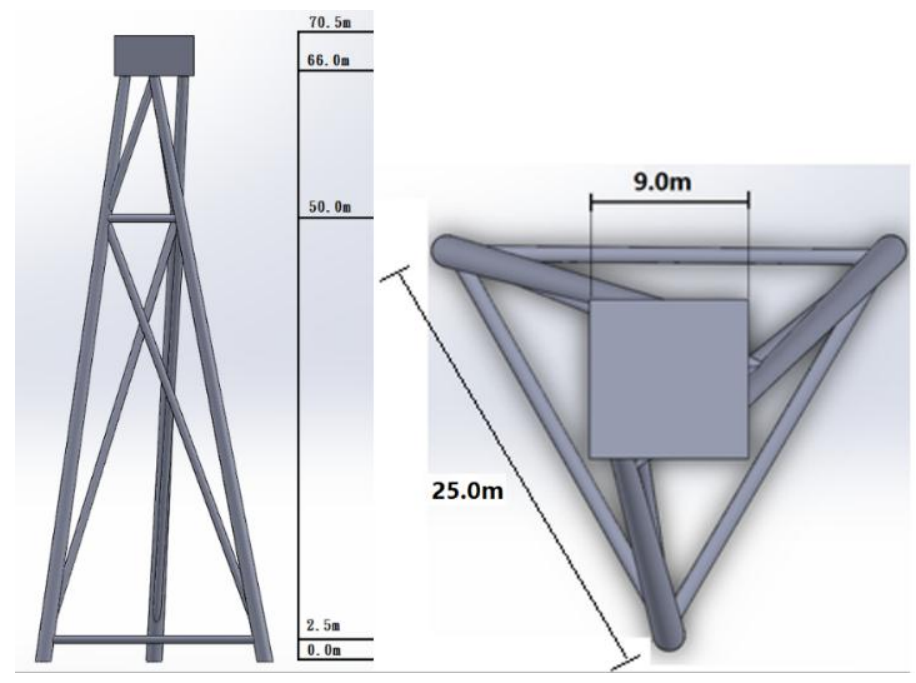

Figure A9. Side and top views of the $60^{\circ}$ tripod (MJ60) structure.

\section{Appendix B. Definitions and Examples of the Terminology for Jacket Structural Members and Parts}

Abbreviations were defined at four levels: (1) $\alpha,(2) \beta$, (3) $\gamma$ and (4) $\delta$. Members and parts were termed in the order of $\alpha \beta \gamma$, and the parts (location) of the members were termed $\alpha \beta \gamma \delta$ (Table 1 ). Examples are given for all four types of substructures.

Abbreviations of the first two levels for all four types of substructures are shown in Figures A10-A13. For instance, "I" is the face normal to the positive $\mathrm{x}$-axis, and others are defined accordingly in the clockwise manner; Level $\beta$ is defined from top to bottom. A number of examples to abbreviate a member or a part of the structure are given in the figures, as well.

It is noted that because of their special design, the TJ-structures are given for a few specific abbreviations that are not used for other structures. For example, structural members and parts of the TJ-structures do not require an abbreviation for the three faces. Instead, the legs and central column require specific abbreviations at Level $\alpha$. In addition, “U, I, D" are abbreviated for members at particular positions (Figure A11). 

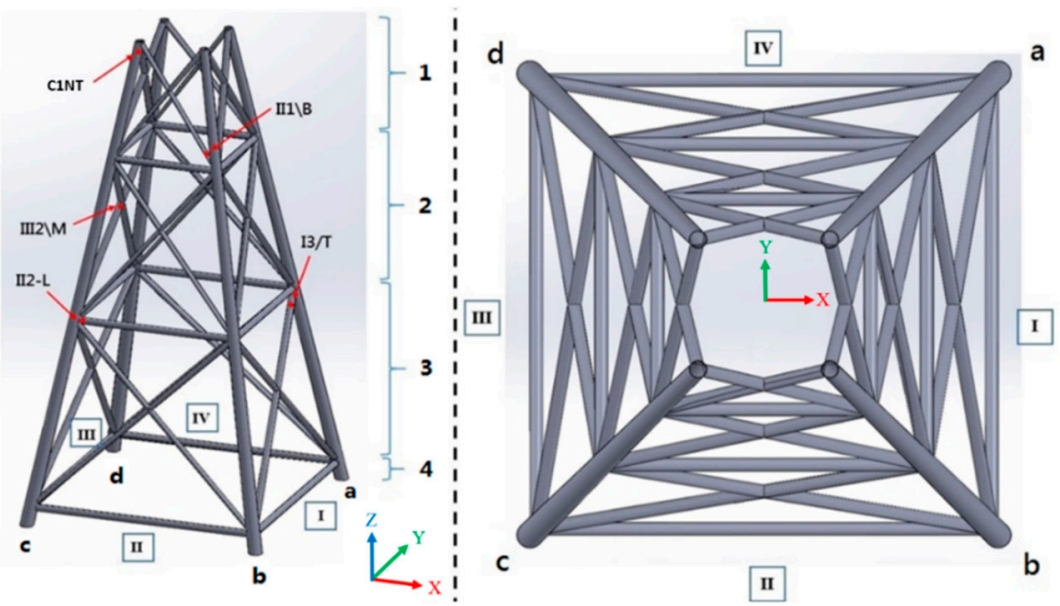

Figure A10. Four levels of abbreviations and examples used for J-structure members and parts.

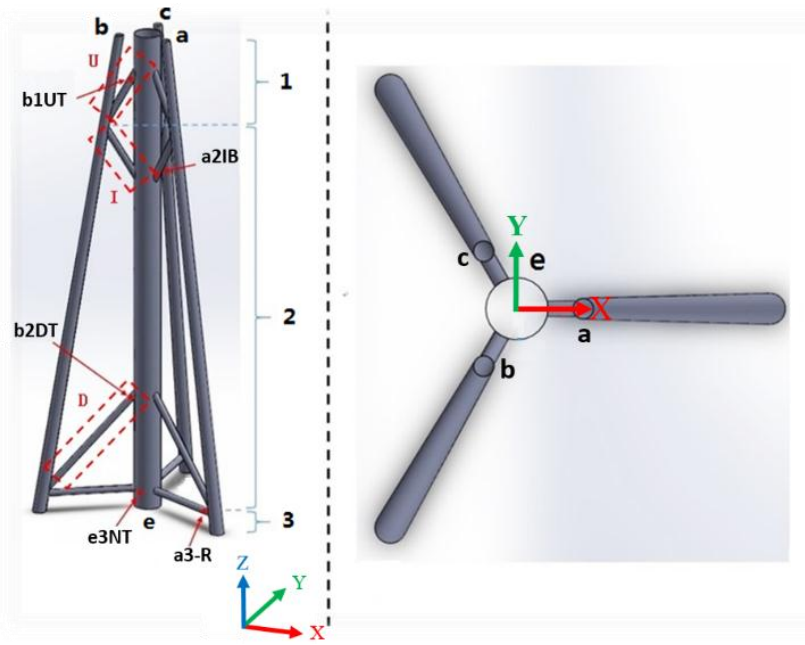

Figure A11. Four levels of abbreviations and examples used for TJ-structure members and parts.

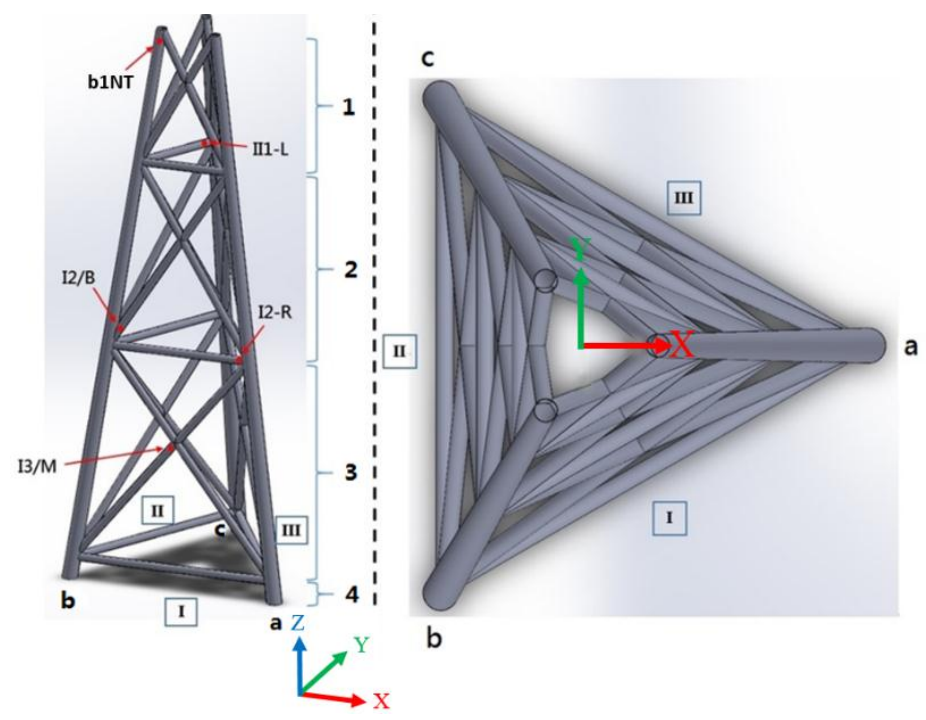

Figure A12. Four levels of abbreviations and examples used for PJ-structure members and parts. 


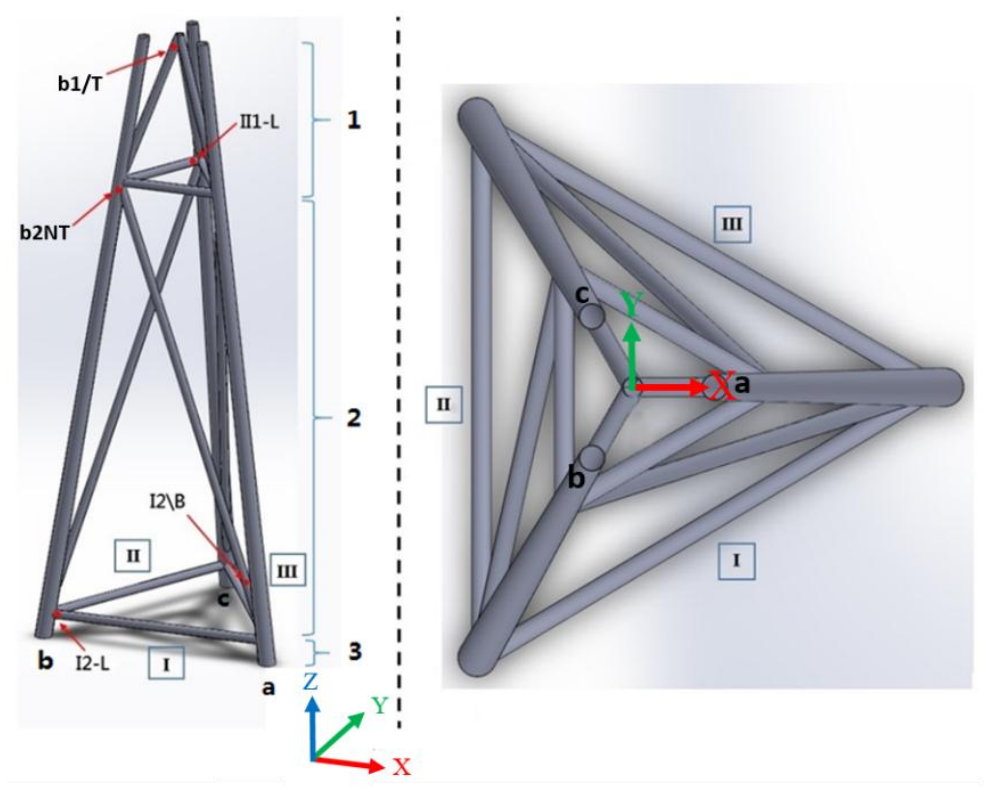

Figure A13. Four levels of abbreviations and examples used for MJ-structure members and parts.

\section{Appendix C. Detailed Description of Load Settings}

\section{C.1. General Information}

The normal condition considered refers to local oceanographic data collected near Pescadores Islands (Penghu). Annual average wind speed, average wave height, average wave period and average speed of ocean currents were set to $7.5 \mathrm{~m} / \mathrm{s}, 0.49 \mathrm{~m}, 7.5 \mathrm{~s}$ and $0.134 \mathrm{~m} / \mathrm{s}$, respectively, for the normal condition [32]. In this load combination, we simply assumed that the wind, wave and current loads act in the same horizontal direction and that the resultant forces and moment are solely in-plane (Figure A14). The extreme condition considered assumes the wind speed, wave height, wave period and speed of ocean currents equal to $70 \mathrm{~m} / \mathrm{s}, 14.88 \mathrm{~m}, 12.47 \mathrm{~s}$ and $1.4 \mathrm{~m} / \mathrm{s}$, respectively.

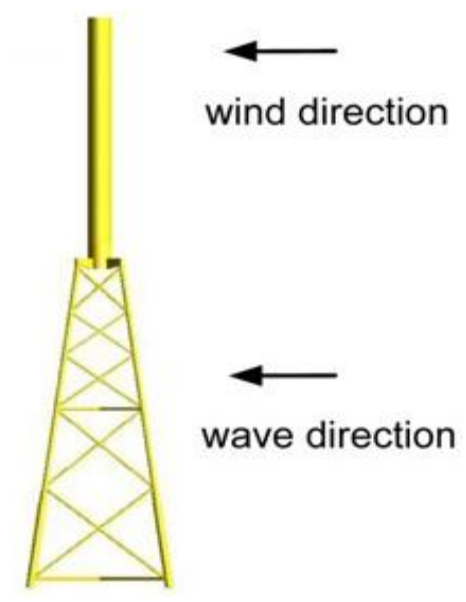

Figure A14. Schematic showing the in-plane winds and waves in the same direction. 


\section{C.2. Wind Load}

The wind forces on blades and on a unit height of a tower are expressed by $\mathrm{F}_{1}$ and $\mathrm{f}_{2}$, respectively (Figure A15a). The resulting base shear and the base overturning moment are given by Equations (A1) and (A2) [36].

$$
\begin{gathered}
\mathrm{F}=F_{1}+\int_{0}^{H} f_{2}(z) d z=\frac{1}{2} \rho_{\text {air }} U_{H}^{2} C_{f} A+\int_{0}^{H} \frac{1}{2} \rho_{\text {air }} U(z)^{2} C_{D} D(z) z d z \\
M=F_{1} H+\int_{0}^{H} f_{2}(z) z d z=\frac{1}{2} \rho_{\text {air }} U_{H}^{2} C_{f} A H+\int_{0}^{H} \frac{1}{2} \rho_{\text {air }} U(z)^{2} C_{D} D(z) z d z
\end{gathered}
$$

where $\mathrm{H}$ is the height from the ground to the center of the hub, $\rho_{\mathrm{air}}$ is the air density, $\mathrm{U}_{\mathrm{H}}$ is the mean wind speed at the height, $C_{f}$ is the wind force coefficient for the blades, $C_{D}$ is the drag force coefficient for the tower, $A$ is the reference area for the blades, $D(z)$ is the diameter of the tower and $z$ is the height of the tower. In Equation (A1), the integrated thrust force acting on the complete rotor was considered (denoted $F_{1}$ ), while the drag force acting on the tower was considered as a distributed force shown in the second term. The profile of the wind force on the tower can be assumed to be any function. In Equations (A1) and (A2), that is assumed to the same as the velocity pressure at the height $\mathrm{z}$.

The governing equations to describe the airflow around a stationary wind turbine are described by the time-averaged continuity and momentum equations together with a k- $\omega$ turbulence model, where the flow solver StarCCM+ is employed to calculate the fully-three-dimensional flow around the wind turbine at the wind speed of $70 \mathrm{~m} / \mathrm{s}$. The corresponding wind loading is given in Table A5, where the coordinate system and the force/moment definition are depicted in Figure A15b.

(a)

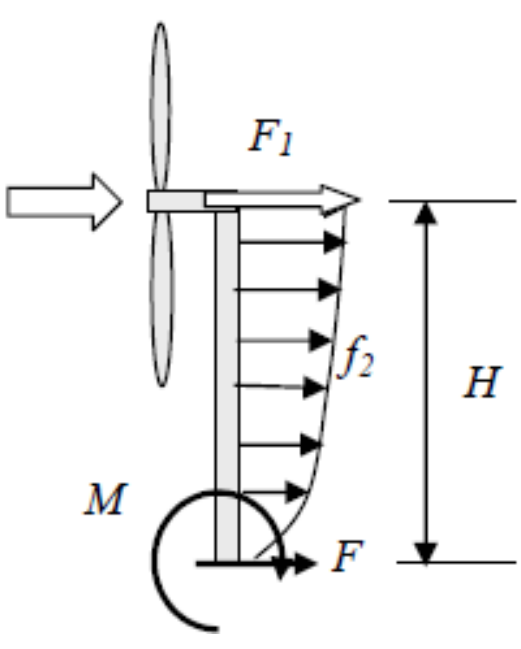

(b)

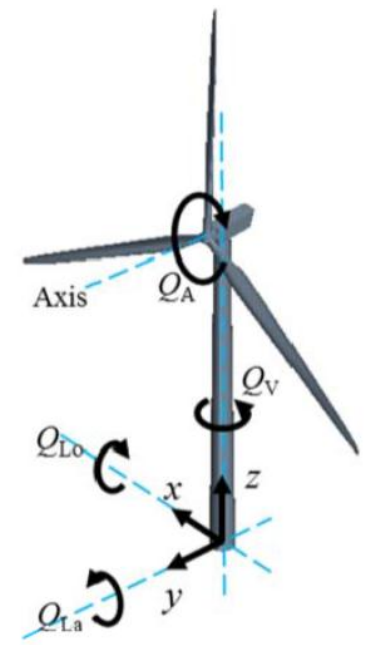

Figure A15. (a) Schematic of planar wind forces on a wind turbine [36]; (b) schematic of 3D wind load settings.

Table A5. Comprehensive (3D) wind loads under the extreme condition.

\begin{tabular}{cccccccc}
\hline Wind Speed & Component & $\mathbf{F}_{\mathbf{x}}$ & $\mathbf{F}_{\mathbf{y}}$ & $\mathbf{F}_{\mathbf{z}}$ & $\mathbf{Q}_{\text {Lo }}$ & $\mathbf{Q}_{\text {La }}$ & $\mathbf{Q}_{\mathbf{v}}$ \\
\hline \multirow{2}{*}{$70 \mathrm{~m} / \mathrm{s}$} & Blade & $-38.948 \mathrm{kN}$ & $-118.5 \mathrm{kN}$ & $411.21 \mathrm{kN}$ & $13.89 \mathrm{MN}-\mathrm{m}$ & $5.38 \mathrm{MN}-\mathrm{m}$ & $0.849 \mathrm{MN}-\mathrm{m}$ \\
& Nacelle & $-5.177 \mathrm{kN}$ & $-10.226 \mathrm{kN}$ & $0.405 \mathrm{kN}$ & $0.975 \mathrm{MN}-\mathrm{m}$ & -0.454 & $6.556 \mathrm{kN}-\mathrm{m}$ \\
& Tower & $261.2 \mathrm{MN}$ & $-315.11 \mathrm{kN}$ & $37.953 \mathrm{kN}$ & $11.397 \mathrm{MN}-\mathrm{m}$ & $4.705 \mathrm{MN}-\mathrm{m}$ & $-1.354 \mathrm{kN}-\mathrm{m}$ \\
\hline
\end{tabular}




\section{C.3. Wave and Current Loads}

The sectional force $\mathrm{df}_{\mathrm{N}}$ on a fixed slender structure in $2 \mathrm{D}$ flow normal to the member axis is given by Morison's load formula [30,31]:

$$
d f_{N}(t)=\rho\left(1+C_{A}\right) A \dot{v}+\frac{1}{2} \rho C_{D} D v|v|
$$

where:

$$
\begin{aligned}
& \mathrm{v}=\text { fluid particle }(\text { waves and } / \text { or current) velocity }(\mathrm{m} / \mathrm{s}) \\
& \dot{v}=\text { fluid particle acceleration }\left(\mathrm{m} / \mathrm{s}^{2}\right) \\
& \mathrm{A}=\text { cross-sectional area }\left(\mathrm{m}^{2}\right) \\
& \mathrm{D}=\text { diameter or typical cross-sectional dimension }(\mathrm{m}) \\
& \rho=\text { mass density of fluid }\left(\mathrm{kg} / \mathrm{m}^{3}\right) \\
& C_{A}=\text { added mass coefficient }(\text { with cross-sectional area as the reference area) } \\
& C_{D}=\text { drag coefficient }
\end{aligned}
$$

The mass coefficient is then defined as $C_{M}=1+C_{A}$. Wave and current loads for the simplified (2D) case were calculated using Morison's equation and Airy's linear theory and assumed in-plane motion as depicted in Figure A14. For the wave load, the drag force was neglected for simplicity, so that only the first term (the inertia force) on the right-hand side of Equation (A3) was taken into consideration. For the current load, on the other hand, the inertia force was neglected. For instance, the wave load is given by:

$$
d f_{\text {wave }}=\rho C_{M} A \dot{v}
$$

where the maximum magnitude of the sinusoidal fluid particle acceleration, $\dot{v}_{m a x}=\frac{4 \pi^{2} a}{T^{2}} \exp \left(\frac{4 \pi^{2}}{g T^{2}} z\right)$, was considered in Equation (A4) for static analysis. The wave load therefore assumed the form:

$$
d f_{\text {wave }}(\mathbf{z})=\rho C_{M} A \frac{4 \pi^{2} a}{T^{2}} \exp \left(\frac{4 \pi^{2}}{g T^{2}} z\right)
$$

where $z=0$ is the location at sea level, $z=-D_{w}$ is at the sea bed, a is the wave height, $T$ is the wave period and $g$ is the gravitational acceleration.

The wave load was further assumed constant, for simplicity, from the sea level to the depth $\mathrm{d}_{\mathrm{c}}$. The depth, $\mathrm{d}_{\mathrm{c}}$, and the amplitude of the constant wave load, $\mathrm{df}_{\mathrm{avg}}$, were obtained, so that the resultant wave force of the constant load (equal to $d f_{\text {wave }} \cdot d_{c}$ ) is identical to that of the load from the linear theory. Hence:

$$
\begin{gathered}
\frac{d_{c}}{2}=\frac{\int_{-D_{w}}^{a} z \cdot d f_{\text {wave }}(\mathbf{z}) d z}{\int_{-D_{w}}^{a} d f_{\text {wave }}(\mathbf{z}) d z} \\
d f_{\text {avg }}=\frac{\int_{-D_{w}}^{a} d f_{\text {wave }}(\mathbf{z}) d z}{\left|d_{c}\right|}
\end{gathered}
$$

The wave and current loads for the comprehensive (3D) case were calculated using Morison's equation and the nonlinear immediate-depth fifth-order Stokes' wave theory. For the three-legged structures (all structures, except J-structures), the wave and current loads were applied in the principal direction, whereas for the four-legged structures (J-structures in this study), these loads were applied in the diagonal direction. For comprehensive understanding of Morison's equations for determining the wind, wave and current loads on circular cylindrical structural members of fixed offshore structures, the readers are referred to $[37,38]$. 


\section{C.4. Calculated Loads for Simulations}

Consider the mass density of the air to be $1.293 \mathrm{~kg} / \mathrm{m}^{3}$, that of the water $1000 \mathrm{~kg} / \mathrm{m}^{3}$, the drag coefficient 0.9 and the mass coefficient 1.0. The calculated simplified (2D) loads were as follows: the self-weight of the baseline wind turbine machine and tower is $1.859 \mathrm{MN}$; the side wind load is $16.644 \mathrm{kN}$; the wind load moment is $733.584 \mathrm{kN}-\mathrm{m}$; the wind load is $32.73 \mathrm{D} \mathrm{N} / \mathrm{m}$, the wave load 200.38A N/m and the current load 8.08D N/m (Figure A16), where D and A are the diameter and the cross-sectional area of the tubular structural members, respectively. Here, the wind, wave and current loads are distributed loads for the beam element models. Moreover, the comprehensive (3D) loads were as follow: the self-weight of the baseline wind turbine machine and tower is $1.859 \mathrm{MN}$; wind loads are given in Table A5; wave loads are complex and various at different locations, so they are not specified in the Appendix C.

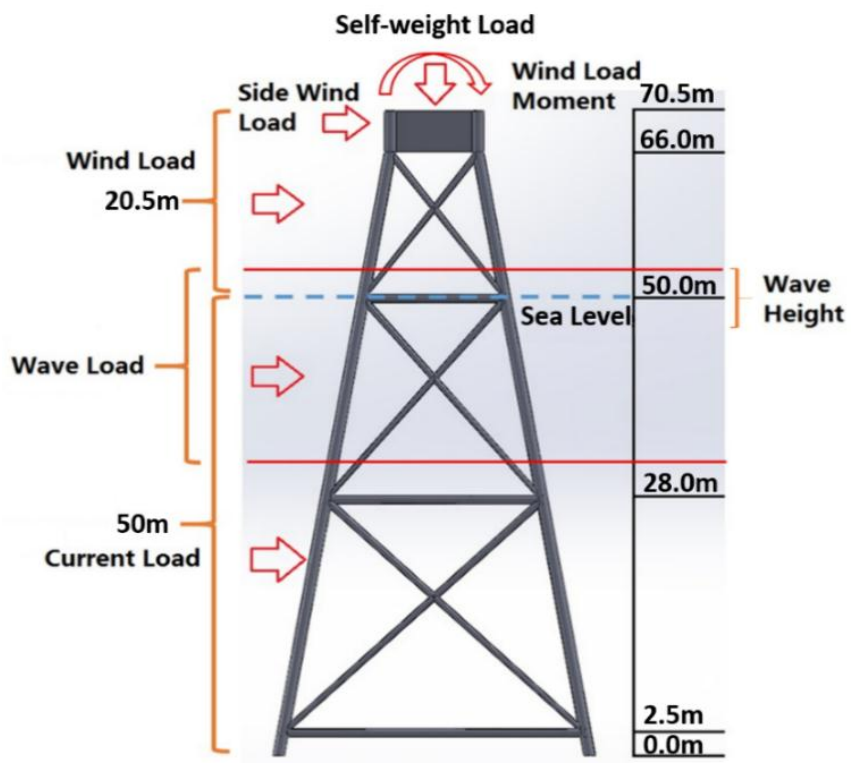

Figure A16. Schematic of the simplified (2D) loads for jacket substructures.

\section{References}

1. Li, K.; Bian, H.; Liu, C.; Zhang, D.; Yang, Y. Comparison of geothermal with solar and wind power generation systems. Renew. Sustain. Energy Rev. 2015, 42, 1464-1474. [CrossRef]

2. Dai, K.; Bergot, A.; Liang, C.; Xiang, W.N.; Huang, Z. Environmental issues associated with wind energy-A review. Renew. Energy 2015, 75, 911-921. [CrossRef]

3. Baker, C. Wind engineering-Past, present and future. J. Wind Eng. Ind. Aerodyn. 2007, 95, 843-870. [CrossRef]

4. Kaldellis, J.K.; Zafirakis, D. The wind energy (r) evolution: A short review of a long history. Renew. Energy 2011, 36, 1887-1901. [CrossRef]

5. Global Wind Energy Concil (GWEC). Global Wind Report-Annual Market Update 2014; Global Wind Energy Concil: Brussels, Belgium, 2015.

6. The European Wind Energy Association (EWEA). The European Offshore Wind Industry-Key Trends and Statistics 1st half 2015; The European Wind Energy Association: Brussels, Belgium, 2015.

7. Vries, W.E. Assessment of Bottom-Mounted Support Structure Types with Conventional Design Stiffness and Installation Techniques for Typical Deep Water Sites; Deliverable Report D4.2.1 (WP4: Offshore foundation and support structures); The European Wind Energy Association: Brussels, Belgium, 2007.

8. Lesny, K.; Richwien, W. Design, Construction and Installation of Support Structures for Offshore. Wind Energy Systems Global Wind Report-Annual Market Update Optimising Design and Construction for Safe and Reliable Operation; Sørensen, J.D., Sørensen, J.N., Eds.; Woodhead Publishing Limited: Cambridge, UK, 2010. 
9. Golightly, C. Tilting of monopiles long, heavy and stiff; pushed beyond their limits. Available online: http:/ /www.nce.co.uk/Journals/2014/06/03/z/h/d/GE-January-2014-Tilting-of-monopiles-Golightly.pdf (accessed on 17 January 2016).

10. Kaldellis, J.K.; Zafirakis, D.P. Trends, prospects, and R\&D directions in wind turbine technology. Compr. Renew. Energy 2012, 2, 671-724.

11. Musial, W.; Butterfield, S.; Ram, B. Energy from offshore wind. In Proceedings of the Offshore Technology Conference (NREL/CP-500-39450), Houston, TX, USA, 1-4 May 2006.

12. Pérez-Collazo, C.; Greaves, D.; Iglesias, G. A review of combined wave and offshore wind energy. Renew. Sustain. Energy Rev. 2015, 42, 141-153. [CrossRef]

13. Moné, C.; Smith, A.; Maples, B.; Hand, M. 2013 Cost of Wind Energy Review; National Renewable Energy Laboratory (NREL): Golden, CO, USA, 2015.

14. Gong, W. Lattice Tower Design of Offshore Wind Turbine Support Structures. Master's Thesis, Norwegian University of Science and Technology, Trondheim, Norway, June 2011.

15. Fenech, L.; Sant, T.; Muscat, M. Design and cost evaluation of a deep water support structure for a wind turbine in central mediterranean waters. In Proceedings of the European Wind Energy Conference, Brussels, Belgium, 14-17 March 2011.

16. Shi, W.; Park, H.C.; Chung, C.W.; Kim, Y.C. Comparison of dynamic response of monopole, tripod and jacket foundation system for a 5-MW wind turbine. In Proceedings of the 21th International Offshore and Polar Engineering Conferenece, Maui, HI, USA, 19-24 June 2011.

17. Seidel, M. Jacket substructures for the REpower 5M wind turbine. In Proceedings of the Conference European Offshore Wind 2007, Berlin, Germany, 4-6 December 2007.

18. Shi, W.; Park, H.; Chung, C.; Baek, J.; Kim, Y.; Kim, C. Load analysis and comparison of different jacket foundations. Renew. Energy 2013, 54, 201-210. [CrossRef]

19. Sun, X. Structure form selection of wind turbine towers. Sciencepaper Online, 2013. Available online: http:/ / www.paper.edu.cn/download/downPaper/201302-190 (accessed on 14 January 2016).

20. Shi, W.; Park, H.; Han, J.; Na, S.; Chang, W. A study on the effect of different modeling parameters on the dynamic response of a jacket-type offshore wind turbine in the Korean southwest sea. Renew. Energy 2013, 58, 50-59. [CrossRef]

21. Alanjari, P.; Asgarian, B.; Bahaari, M.R.; Honarvar, M.R. On the energy dissipation of jacket type offshore platforms with different pile-leg interactions. Appl. Ocean Res. 2009, 31, 82-89. [CrossRef]

22. Alanjari, P.; Asgarian, B.; Kia, M. Nonlinear joint flexibility element for the modeling of jacket-type offshore platforms. Appl. Ocean Res. 2011, 33, 147-157. [CrossRef]

23. Hall, R.A.; Shaw, R.L. Offshore Structure Support. U.S. Patent 7,942,611 B2, 17 May 2011.

24. Hall, R.A. Offshore Support Structure and Associated Method of Installing. U.S. Patent 8,511,940 B2, 20 August 2013.

25. Keystone Keystone Engineering Inc., Inward Battered Guide Structure-The “Twisted Jacket", Keystone Engineering IBGS brochure 2.0, 2015. Available online: http://issuu.com/keystoneengineering/docs/ ibgs_brochure_2.0/5?e=0/10933386 (accessed on 9 January 2016).

26. Li, P. Analysis and Design of Offshore Jacket Wind Turbine. Master's Thesis, Norwegian University of Science and Technology, Trondheim, Norway, June 2010.

27. Jonkman, J.M.; Butterfield, S.; Musial, W.; Scott, G. Definition of a 5-MW reference wind turbine for offshore system development. National Renewable Energy Laboratory 2009, 1. [CrossRef]

28. Vries, W.D.; Vemula, N.K.; Passon, P.; Fischer, T.; Kaufer, D.; Matha, D. Support Structure Concepts for Deep Water Sites: Deliverable D4.2.8 (WP4: offshore foundations and support structures); The European Wind Energy Association: Brussels, Belgium, 2011.

29. Chew, K.H.; Ng, E.Y.K.; Tai, K. Offshore wind turbine jacket substructure: A comparison study between four-legged and three-legged designs. J. Ocean Wind Energy 2014, 1, 77-81.

30. Det Norske Veritas-Germanischer Lloyd (DNV GL). Recommended Practice DNV-OS-J101_Design of Offshore Wind Turbine Structures; DNV GL: Høvik, Norway, 2014.

31. Det Norske Veritas-Germanischer Lloyd (DNV GL). Recommended Practice DNV-RP-C201-Environmental Conditions and Environmental Loads; DNV GL: Høvik, Norway, 2010.

32. Su, C.H.; Liaw, C.T. Oceanographical Observation Data-Annual Report 2011 (Penghu Harbor); Harbor \& Marine Technology Center: Taipei, Taiwan, 2013. 
33. Menter, F.R. Two-equation eddy-viscosity turbulence modeling for engineering applications. AIAA J. 1994, 32, 1598-1605. [CrossRef]

34. Abaqus 6.14. Abaqus Analysis User's Guide; Dassault Systèmes Simulia Corp.: Providence, RI, USA, 2015.

35. N-004 Design of Steel Structures (Rev 3). Available online: https://www.standard.no/en/sectors/ energi-og-klima/petroleum/norsok-standard-categories/n-structural/n-0042/ (accessed on 1 August 2015).

36. Kawai, H.; Michishita, K.; Deguchi, A. Design Wind Loads on a Wind Turbine for Strong Wind, Proceedings of the BBAA VI International Colloquium on: Bluff Bodies Aerodynamics \& Applications, Milano, Italy, 20-24 July 2008.

37. Morison, J.R. The Force Distribution Exerted by Surface Waves on Piles; University of California: Berkeley, CA, USA, 1950.

38. Faltinsen, O.M. Sea Loads on Ships and Offshore Structures, 1st ed.; Cambridge University Press: Cambridge, UK, 1990; pp. 174-256.

(C) 2016 by the authors; licensee MDPI, Basel, Switzerland. This article is an open access article distributed under the terms and conditions of the Creative Commons by Attribution (CC-BY) license (http://creativecommons.org/licenses/by/4.0/). 